\title{
Effect of Loop Diameter on the Steady State and Stability Behaviour of Single-Phase and Two-Phase Natural Circulation Loops
}

\author{
P. K. Vijayan, A. K. Nayak, D. Saha, and M. R. Gartia \\ Reactor Engineering Division, Bhabha Atomic Research Centre, Trombay, Mumbai 400085, India \\ Correspondence should be addressed to P. K. Vijayan, vijayanp@barc.gov.in
}

Received 1 June 2007; Revised 14 December 2007; Accepted 29 February 2008

Recommended by John Cleveland

In natural circulation loops, the driving force is usually low as it depends on the riser height which is generally of the order of a few meters. The heat transport capability of natural circulation loops (NCLs) is directly proportional to the flow rate it can generate. With low driving force, the straightforward way to enhance the flow is to reduce the frictional losses. A simple way to do this is to increase the loop diameter which can be easily adopted in pressure tube designs such as the AHWR and the natural circulation boilers employed in fossil-fuelled power plants. Further, the loop diameter also plays an important role on the stability behavior. An extensive experimental and theoretical investigation of the effect of loop diameter on the steady state and stability behavior of single- and two-phase natural circulation loops have been carried out and the results of this study are presented in this paper.

Copyright (c) 2008 P. K. Vijayan et al. This is an open access article distributed under the Creative Commons Attribution License, which permits unrestricted use, distribution, and reproduction in any medium, provided the original work is properly cited.

\section{INTRODUCTION}

Natural circulation systems find application in many nuclear reactor systems. Single-phase natural circulation is the mode of coolant circulation in the current pressurized water and heavy water reactors (PWRs and PHWRs) following a pumping power failure. Certain reactor systems like the heating reactors (normally referred to as district heating reactors [1]) and the CAREM PWR [2] use single-phase natural circulation as the normal mode of coolant circulation in the primary system. Two-phase natural circulation systems are extensively used in fossil-fuelled power plants, thermosyphon reboilers, and steam generators including those in nuclear power reactors like PWRs, VVERs, and PHWRs. Two-phase natural circulation is the mode of coolant circulation in the current generation of nuclear power plants following a small break LOCA associated with pumping power failure. It was used as the normal mode of coolant circulation in low power boiling water reactors (BWRs) like Humbholdt Bay 3 (63 MWe), Dodewaard (65 MWe), and VK-50 (50 MWe). In many new designs under development like the ESBWR, AHWR [3], and VK-300 [4], two-phase natural circulation is the normal mode of coolant circulation.
Natural circulation based reactor designs are being studied even with supercritical water as coolant $[5,6]$.

In view of their wide application, both single-phase and two-phase natural circulation systems are being extensively studied. State-of-the-art reviews on single-phase $[7,8]$ and two-phase $[9,10]$ natural circulation have been provided by several authors. Most studies are concerned with instability as natural circulation systems are more unstable than forced circulation systems. For example, both single-phase and twophase NCSs exhibit instability whereas only two-phase forced circulation systems are known to exhibit instability. Apart from the steady-state performance, operational transients like start-up, power raising and step back are also required to be stable for natural circulation reactors. This requires specification of a stable operating procedure which in turn requires deeper understanding of the parametric trends due to the operational (i.e., inlet subcooling, pressure, and power) and the geometric parameters (i.e., height, diameter, and orientation of source; and sink) affecting natural circulation.

In the present paper, the effect of loop diameter on the steady state and stability behavior of single- and two-phase natural circulation loops was studied both experimentally 


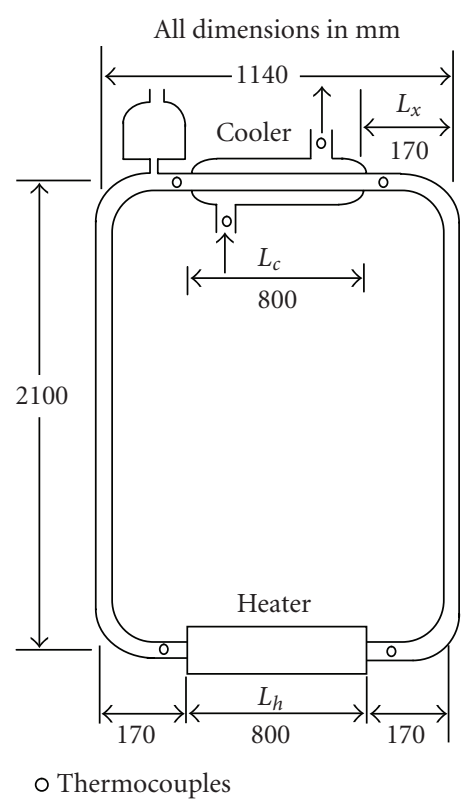

(a)

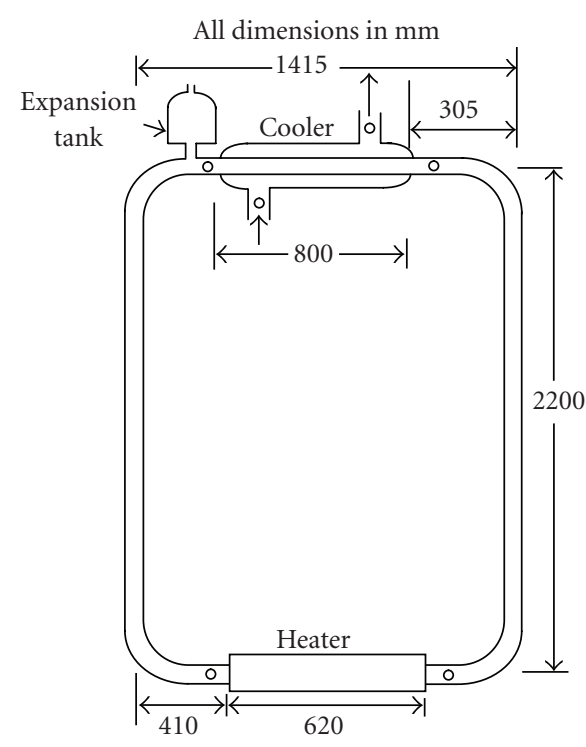

o Thermocouples

(b)

FIgURE 1: Schematic of the experimental loops.

and theoretically. Single-phase natural circulation is found to destabilize with increase in loop diameter. On the other hand, the two-phase natural circulation is found to stabilize with increase in loop diameter. Both the type-I and type-II instabilities in two-phase loops are found to be significantly influenced by the loop diameter. For example, the threshold value of pressure at which type-I instability disappears is found to decrease with increase in loop diameter. TypeII instability was observed only in small diameter loops. Linear analysis showed that type-II instability does not occur in the two-phase region $(0<$ quality $<1)$ if the loop diameter is above a critical value. Depending on the loop diameter, the maximum operating power of a natural circulation system can be either stability controlled or critical heat flux (CHF) controlled. For stability controlled systems, the minimum decay ratio (DR) line can be an ideal operating line. Premature occurrence of CHF and burnout is a serious concern during low-frequency and high-amplitude oscillatory flows in small diameter loops.

\section{SINGLE-PHASE NATURAL CIRCULATION}

Even for natural circulation based boiling water reactors, single-phase natural circulation is encountered during the heat-up phase. Hence experiments were carried out in four single channel uniform diameter loops (UDLs) of rectangular shape made of borosilicate glass tube having horizontal heater and cooler with diameter varying from $6 \mathrm{~mm}$ to $26.9 \mathrm{~mm}$. These studies were carried out at near atmospheric conditions. Three of the loops studied had the general dimensions as shown in Figure 1(a) and the dimensions of the fourth loop are shown in Figure 1(b). The cooler was tube-in-tube type and the heater was made by winding nichrome wire uniformly on the outside of the tube. The experimental loops had a small expansion tank open to the atmosphere to accommodate the swell and shrinkage. The measurements included the heater power, loop temperatures and the cooling water flow rate and its inlet temperature. For the loop shown in Figure 1(b), the pressure drop across $1075 \mathrm{~mm}$ of the bottom horizontal pipe was also measured. A data logger with a scanning time of 1.5 seconds recorded all the measurements. The measurement accuracy was $0.4 \%$ $\left( \pm 1.1^{\circ} \mathrm{C}\right)$ for thermocouples, $\pm 2 \%$ for flow rate and $\pm 0.5 \%$ of the span $(0-1250 \mathrm{~W})$ for power and pressure drop $(-100$ to $+100 \mathrm{~Pa})$.

\subsection{Steady state behavior}

Steady state flow prevails when the driving buoyancy force is balanced by the retarding frictional force, that is, $\rho_{0} \beta g \oint T d z=\left(f L_{t} / D\right)\left(W^{2} / 2 \rho_{0} A^{2}\right)$. Integrating over the closed loop and replacing $\Delta T_{h}=Q_{h} / W C p$ and $f=p / \operatorname{Re}^{b}=$ $p A^{b} \mu^{b} / D^{b} W^{b}$, we obtain

$$
W=\left[\frac{2 D^{b} \rho^{2} \beta_{T} g A^{2-b} Q_{h} \Delta z}{p C p \mu^{b} N_{G}}\right]^{1 /(3-b)} .
$$

The above equation is valid for uniform diameter loops with negligible local pressure losses filled with an incompressible Boussinesq fluid, where

$$
\beta_{T}=\frac{1}{v}\left(\frac{\partial v}{\partial T}\right)_{p}
$$

From the steady state experimental data, a heat balance using the measured heater power and the temperature difference across the heater yielded the mass flow rate. For the same 


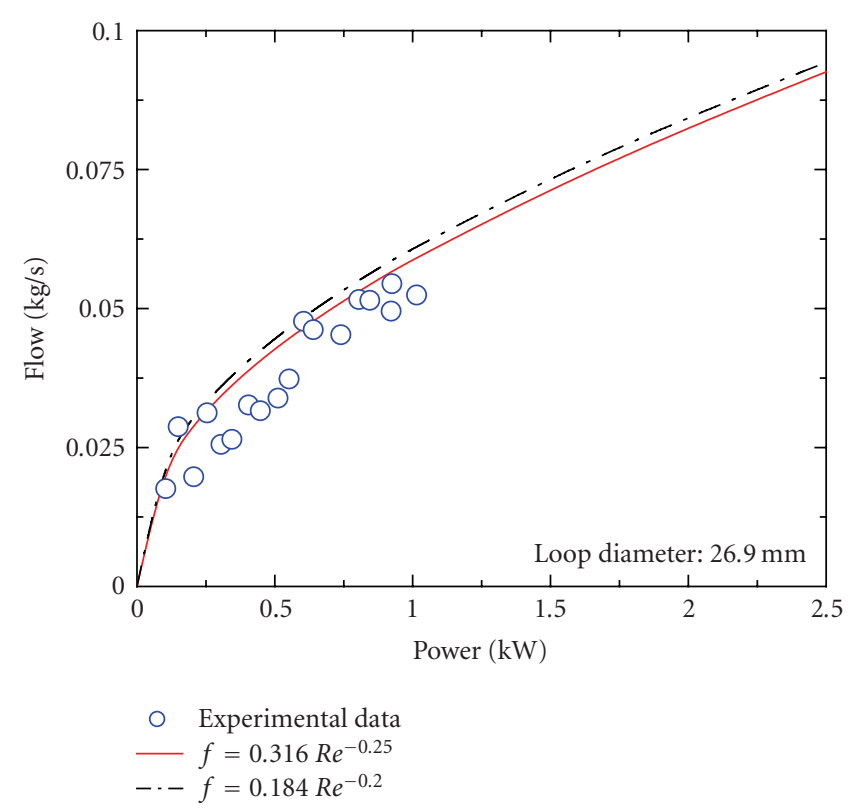

(a) Measured and predicted flow

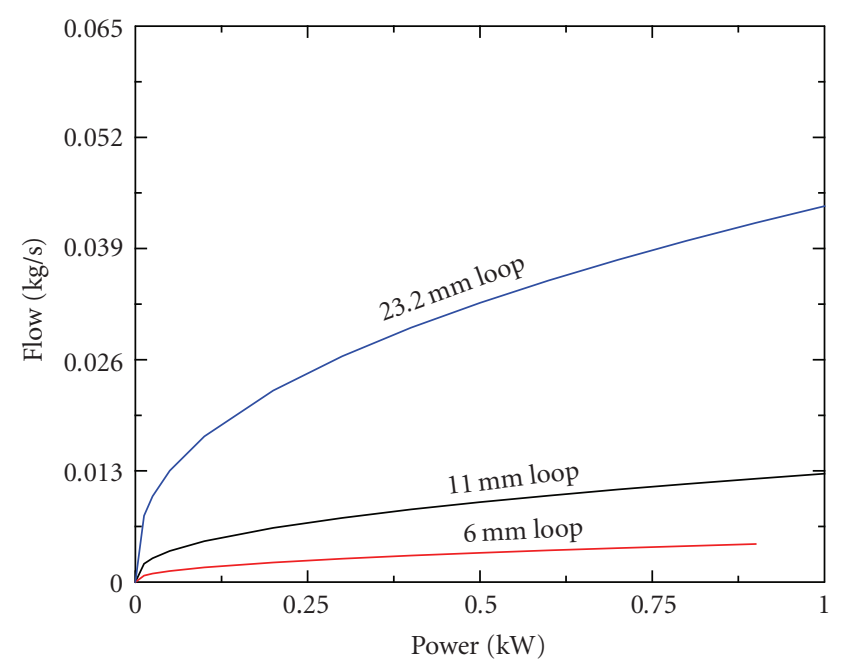

(b) Effect of loop diameter on predicted flow rate

Figure 2: The steady state flow rate variation with power for different loop diameters.

operating conditions (heater power, coolant flow rate and its inlet temperature), the flow rate is found to increase with power and loop diameter (Figure 2). The steady state flow rate can be expressed by the following dimensionless correlation [11]:

$$
\operatorname{Re}_{\mathrm{sS}}=C\left[\frac{\left(\mathrm{Gr}_{m}\right)_{\Delta z}}{N_{G}}\right]^{r}
$$

where $\operatorname{Re}_{s s}=D W_{\text {ss }} / A \mu,\left(\mathrm{Gr}_{m}\right)_{\Delta z}=D^{3} \rho^{2} \beta_{T} g Q_{h} \Delta z /$ $A \mu^{3} C p, N_{G}=L_{t} / D, C=(2 / p)^{r}, r=1 /(3-b), p$ and $b$ are the constants in the friction factor correlation of the form $f=p / \operatorname{Re}^{b}$. The $p$ and $b$ values for laminar, transition and turbulent flows were, respectively, $64 \& 1$,

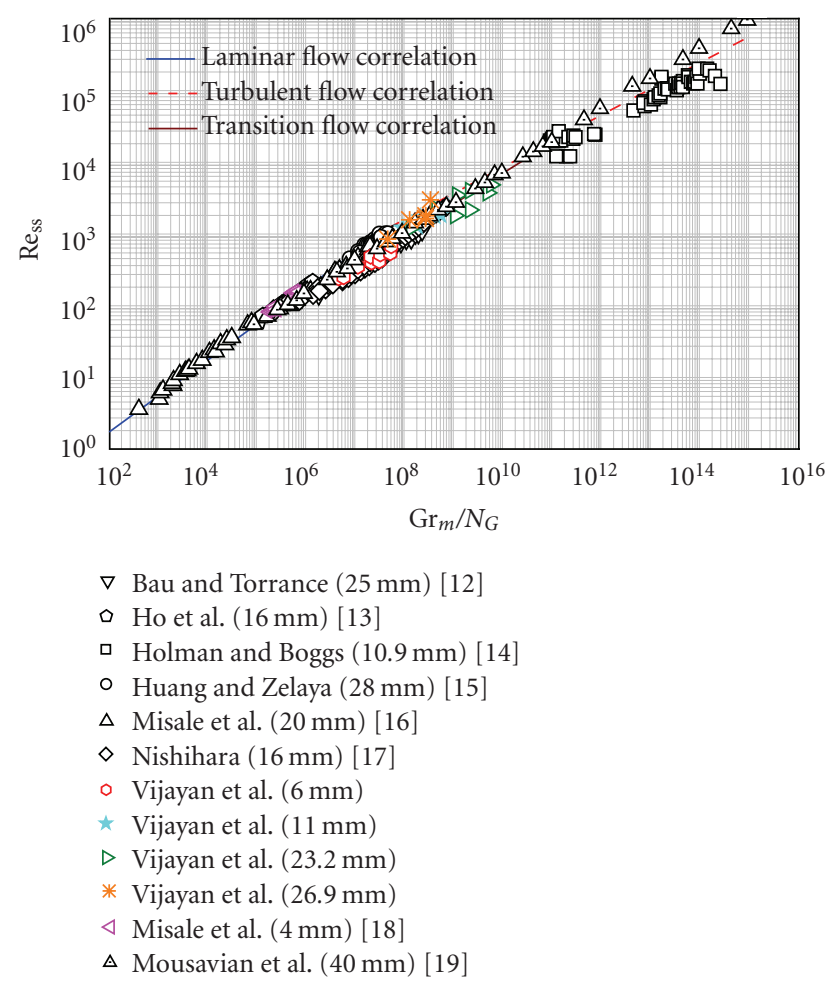

FIGURE 3: Steady state performance of single-phase loops differing in diameter (dimensions in the bracket denote the loop diameter used by different investigators).

$22.3 \& 0.67$, and $0.316 \& 0.25$. Corresponding $C$ and $r$ values for laminar, transition and turbulent flow are, respectively, $0.1768 \& 0.5,0.3568 \& 0.43$, and $1.96 \& 0.364$. The dimensionless steady state flow rate data is compared with (3) for various flow regimes in Figure 3. The literature data on rectangular natural circulation loops [12-19] are also included in Figure 3. The steady state flow rate data agrees reasonably well with the proposed steady state correlations.

\subsection{Stability behavior}

Both theoretical and experimental studies were carried out to understand the stability behavior.

\subsubsection{Test results}

Before stability runs the fluctuations in the loop instrument readings at zero power and steady state operation were established. The fluctuations in the controlled coolant flow rate and its inlet temperature were also noted. The experiments showed that the loops with small diameters were highly stable. However, instability could be observed in $23.2 \mathrm{~mm}$ and $26.9 \mathrm{~mm}$ diameter loops. Extensive investigations of the unstable behavior were carried out for the $26.9 \mathrm{~mm}$ i.d. loop [20-22]. An interesting observation is that the instability threshold is not a unique value but depends on the operating procedure (characteristic of the hysteresis phenomenon). 
Based on the operating procedure, the natural circulation flow can be classified as unconditionally stable, conditionally stable, and unconditionally unstable (Figure 4). In the conditionally stable (hysteresis) region, stable or unstable flow can prevail depending on the operating procedure.

Three different oscillatory modes are observed in the experiment depending on the power. These are unidirectional pulsing (UDP), bidirectional pulsing (BDP), and chaotic switching. UDP is characterized by a bean-shaped limit cycle, whereas BDP is characterized by a dumbbellshaped limit cycle (Figure 4). Between the two, an oscillatory regime with chaotic switching between UDP and BDP is observed. At high powers, the BDP becomes chaotic. The loop resistance and the coolant flow significantly affect the thresholds of a specified oscillatory flow regime.

\subsubsection{Stability analysis}

Derivation of the characteristic equation for the stability parameter $n$ ( $n$ is a complex variable) and its solution procedure are described based on the linear stability method in Vijayan and Nayak [23]. The characteristic equation for the loop shown in Figure 1 can be expressed as

$$
n-\frac{(p / 2)^{1+m}}{\left(\mathrm{Gr}_{m} I_{\mathrm{ss}}\right)^{m}\left(D / L_{t}\right)^{1+m}}\left[\left(\frac{\bar{I}}{\bar{\omega}}\right)-(2-b)\right]=0
$$

where

$$
\begin{gathered}
m=\frac{b}{3-b}, \quad I_{\mathrm{ss}}=\oint \theta_{\mathrm{ss}} d Z, \\
\frac{\bar{I}}{\bar{\omega}}=\frac{\phi}{n}\left(1-e^{-n / \phi}\right) e^{-n L_{x} / L_{t}}\left\{\frac{\bar{\theta}_{h}-\bar{\theta}_{c}}{\bar{\omega}}\right\}, \\
\frac{\bar{\theta}_{h}-\bar{\theta}_{c}}{\bar{\omega}}=\frac{\mathrm{St}_{m}\left(\theta_{\mathrm{hl}}\right)_{\mathrm{ss}} \alpha+\left(L_{t} / L_{h}\right) \alpha^{*}}{n\left(e^{\left(\mathrm{St}_{m} L_{c}+n L_{t}\right) / L_{t}}-1\right)},
\end{gathered}
$$

where $\alpha=\left\{e^{n L_{\mathrm{hl}} / L_{t}}\left(e^{n L_{c} / L_{t}}-1\right)-e^{n}\left(1-e^{-n L_{c} / L_{t}}\right)\right\}$ and $\alpha^{*}=$ $\left\{e^{\left(\mathrm{St}_{m} L_{c}+n L_{t}\right) / L_{t}}\left(e^{-n L_{h} / L_{t}}-1\right)-e^{n L_{\mathrm{c}} / L_{t}}\left(1-e^{n L_{h} / L_{t}}\right)\right\}$. Using the characteristic equation, the stability map was generated for the loops with different diameters. Figures 5(a) and 5(b) show a comparison of the predicted stability map with test data. Considering that the effects of wall conduction, axial conduction in the fluid, the local pressure losses, the heat losses, and multidimensional effects are neglected in these calculations, the agreement with test data is reasonable. The unstable zone is found to shift up with reduction in loop diameter. Thus, increasing the loop diameter is found to destabilize single-phase natural circulation. A literature review has revealed that the $L_{t} / D$ ratio is an important parameter affecting instability. In fact to our knowledge, instability has not been observed experimentally in uniform diameter loops with $L_{t} / D>300$. The stability map, however, is a strong function of the friction correlation (Figure 5(b)).

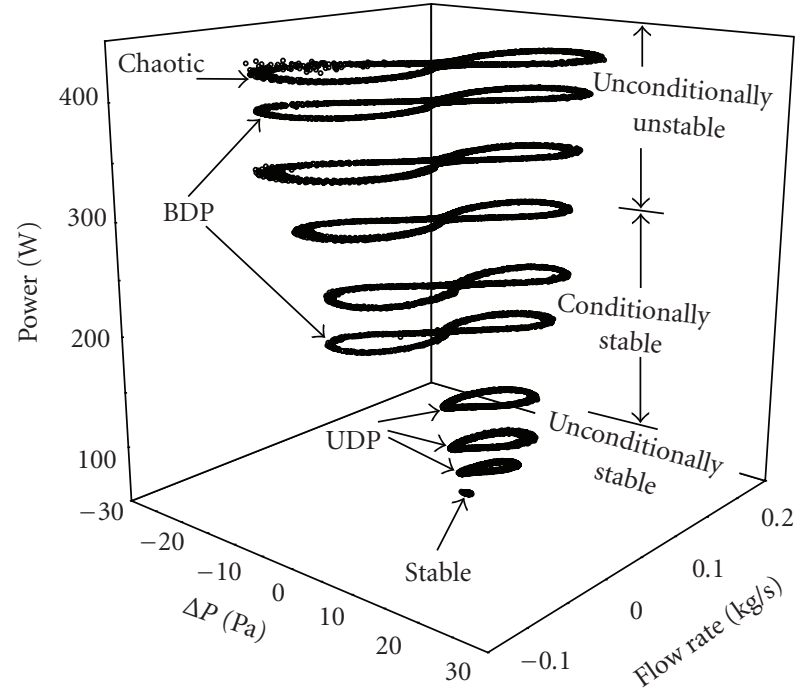

Figure 4: Unstable oscillatory regions in single-phase loops.

\section{TWO-PHASE NATURAL CIRCULATION}

Two-phase natural circulation experiments were conducted in four uniform diameter loops of inside diameter 7, 9.1, 15.74 , and $19.86 \mathrm{~mm}$ with the length scales as shown in Figure 6(a). The steam separator, the condenser, and the associated piping (the portion inside the rectangular box in Figure 6(a)) were the same for all the loops. The steam separator was made of $59 \mathrm{~mm}$ inside diameter pipe. The vertical heater section was directly heated with a high current low voltage power supply. The steam-water mixture produced flows to the separator and the separated steam was condensed and the condensate returns to the steam drum by gravity. The loop was extensively instrumented to measure heater power, temperatures (of heater surface and fluid), steam drum pressure, differential pressure at various sections of the single-phase and two-phase pipes, SD level, flow rates (loop, condensate, and cooling water flows), void fraction and its distribution. The void fraction was measured using both neutron radiography (NRG) and conductance probe (CP). The neutron radiography also helped to visualize the flow patterns. To facilitate neutron radiography, the loop was installed in the Apsara reactor hall in front of the neutron beam hole (Figure 6(b)). With the neutron radiography, void fraction was measured at the outlet of the heated section, whereas conductance probes were located at the center line in the vertical tube above the neutron window as well as in the top near horizontal tube. During the experiments, the system was initially pressurized in the cold condition to the required value with the help of nitrogen cylinders. During the heat-up and boiling, the system pressure increase was compensated by bleeding nitrogen-steam mixture from the condenser. Further details of the loop are available in Vijayan et al. [24] and Dubey et al. [25]. In addition, experimental data were generated in a $49.3 \mathrm{~mm}$ inside diameter loop shown in Figure 6(c). The inside diameter of the heated section was $53.4 \mathrm{~mm}$ in this loop. Further details of this facility are available in Kumar et al. [26]. 


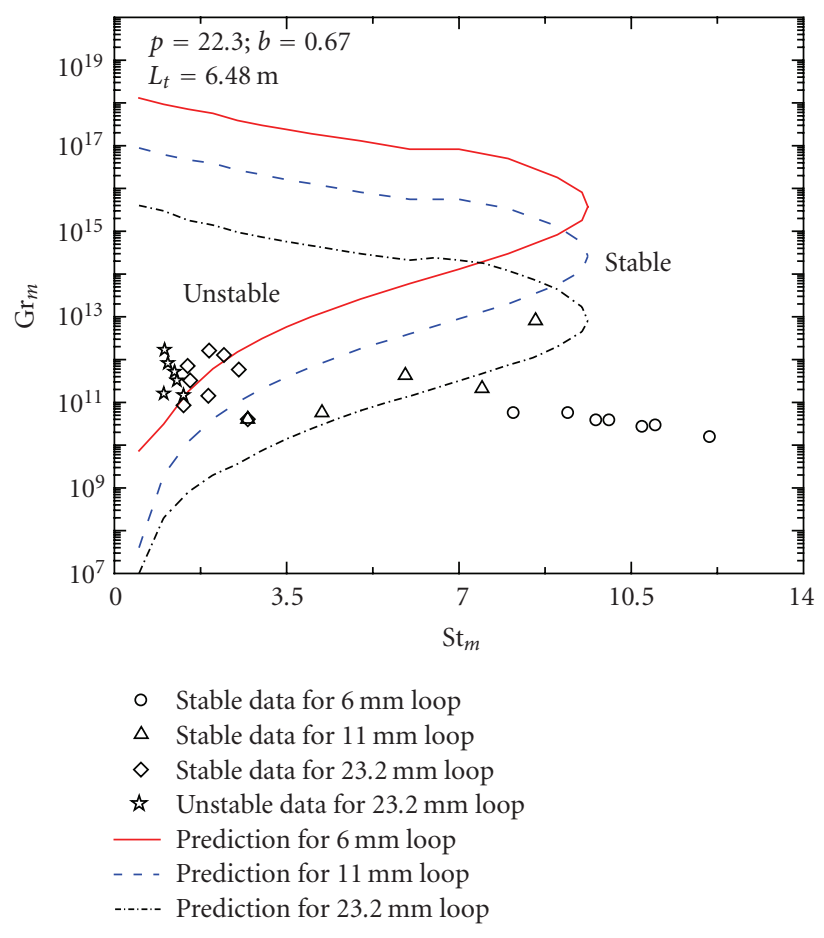

(a) 6, 11 and $23.2 \mathrm{~mm}$ loops

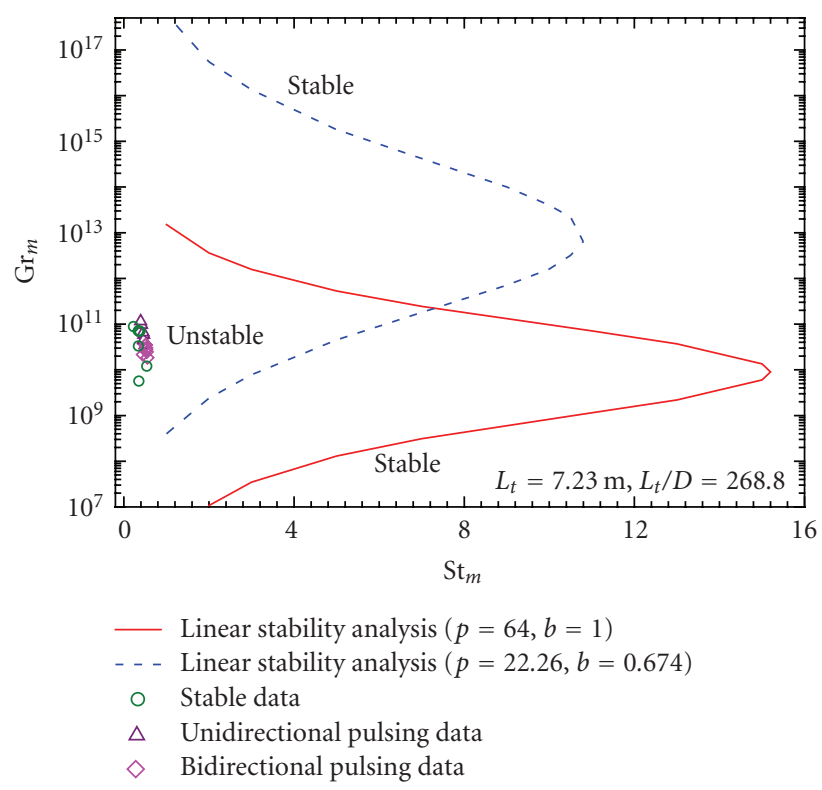

(b) $26.9 \mathrm{~mm}$ loop

FIGURE 5: Comparison of predicted stability map with data.

\subsection{Steady state behavior}

Steady state data on flow pattern, void fraction, and flow rate were collected for the various loops as a function of power at different pressures. The $7 \mathrm{~mm}$ loop was mostly unstable and reliable steady state data could not be generated due to frequent burnout of the heated section. The steady state data generated in all other loops fall in the following range of parameter: loop diameter: $9.1-49.3 \mathrm{~mm}$, circulation length: 8.7 and $13.5 \mathrm{~m}$, SD level: $90 \% \pm 5 \%$, pressure: $0.1-7 \mathrm{MPa}$, quality: $0.4-24 \%$, and power: $0.3-40 \mathrm{~kW}$.

\subsubsection{Flow patterns}

Steady state flow patterns at the exit of the heated section were recorded with a CCD camera, details of which are available in Sinha et al. [27]. The predominant flow pattern observed in all the loops (of geometry given by Figure 6(a)) was bubbly or bubbly-slug. Typical recorded images and the expected flow pattern change with increase in power are shown in Figures 7(a) and 7(b), respectively.

\subsubsection{Void fraction}

The void fraction measured by the neutron radiography and the conductance probe were close to each other. The void fraction data were compared with various correlations giving reasonable agreement. A typical comparison with Ishii correlation [31] is shown in Figure 8. More results on the void fraction are available in $[24,32]$.

\subsubsection{Steady state flow}

The steady state flow rate was measured with the help of calibrated pipe taps located in the single-phase bottom horizontal pipe. Assuming balance of the driving buoyancy force to the retarding frictional forces at steady state, the following equation was derived to estimate the steady state flow rate in a UDL [33]:

$$
W_{\mathrm{ss}}=\left[\frac{2}{p} \frac{D^{b} \rho_{l}^{2} \bar{\beta}_{h} g A^{2-b} Q_{h} \Delta z}{\mu_{l}^{b} N_{G}}\right]^{1 /(3-b)},
$$

which can be expressed in dimensionless form as

$$
\mathrm{Re}_{\mathrm{ss}}=C\left(\frac{\mathrm{Gr}_{m}}{N_{G}}\right)^{r}
$$

where

$$
\mathrm{Gr}_{m}=\frac{D^{3} \rho_{l}^{2} \bar{\beta}_{h} g Q_{h} \Delta z}{A \mu_{l}^{3}} ; \quad \bar{\beta}_{h}=\frac{1}{v}\left(\frac{\partial v}{\partial h}\right)_{p}
$$

$$
N_{G}=\frac{L_{t}}{D}\left[\left(l_{\mathrm{eff}}\right)_{\mathrm{sp}}+\bar{\phi}_{\mathrm{LO}}^{2}\left(l_{\mathrm{eff}}\right)_{B}+\phi_{\mathrm{LO}}^{2}\left(l_{\mathrm{eff}}\right)_{\mathrm{tp}}+\bar{\phi}_{\mathrm{LO}}^{2}\left(l_{\mathrm{eff}}\right)_{c}\right]
$$

with

$$
\begin{gathered}
\phi_{\mathrm{LO}}^{2}=\frac{\rho_{l}}{\rho_{e}}\left[\frac{1}{1+x_{e}\left(\mu_{l} / \mu_{g}-1\right)}\right]^{b}, \\
\bar{\phi}_{\mathrm{LO}}^{2}=\frac{\rho_{l}}{\rho_{m}}\left[\frac{1}{1+\left(x_{e} / 2\right)\left(\mu_{l} / \mu_{g}-1\right)}\right]^{b} .
\end{gathered}
$$




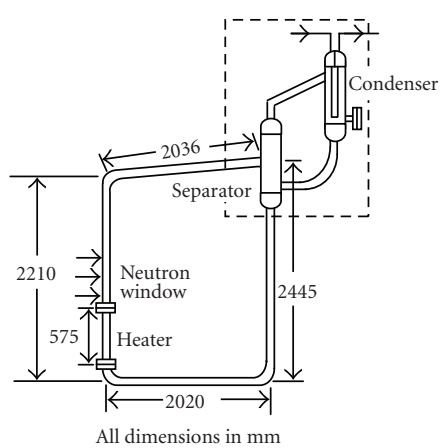

(a)

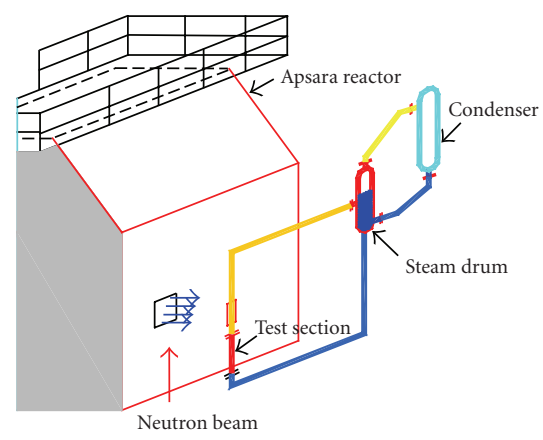

(b)

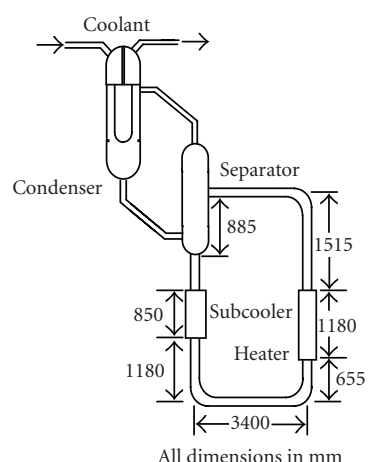

(c)

FIGURE 6: Schematic of the different test loops.
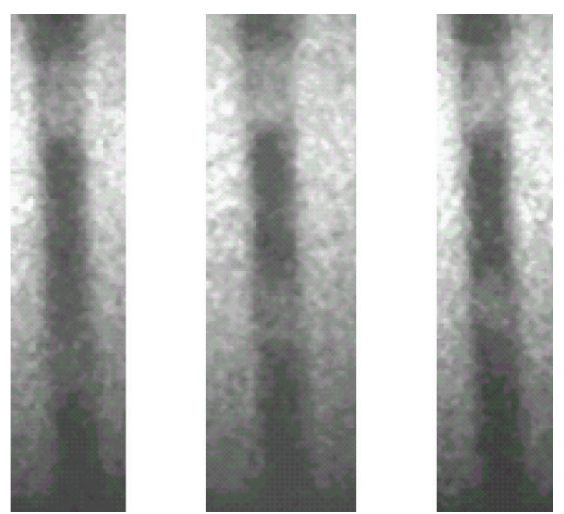

(a) Typical slug flow pattern

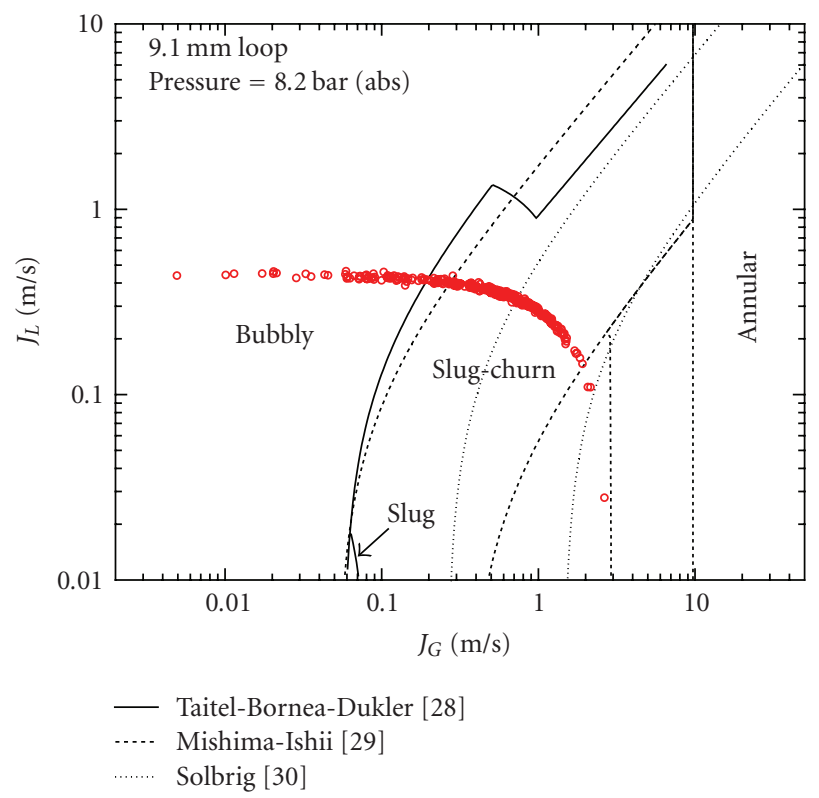

(b) Flow patterns predicted with various flow pattern maps

FIgURE 7: Flow patterns obtained for a typical run.

It may be noted that for single-phase flows $\phi_{\mathrm{LO}}^{2}=1$, and (8) reduces to that applicable to single-phase natural circulation. Also, similarity in the definitions of the thermal expansion

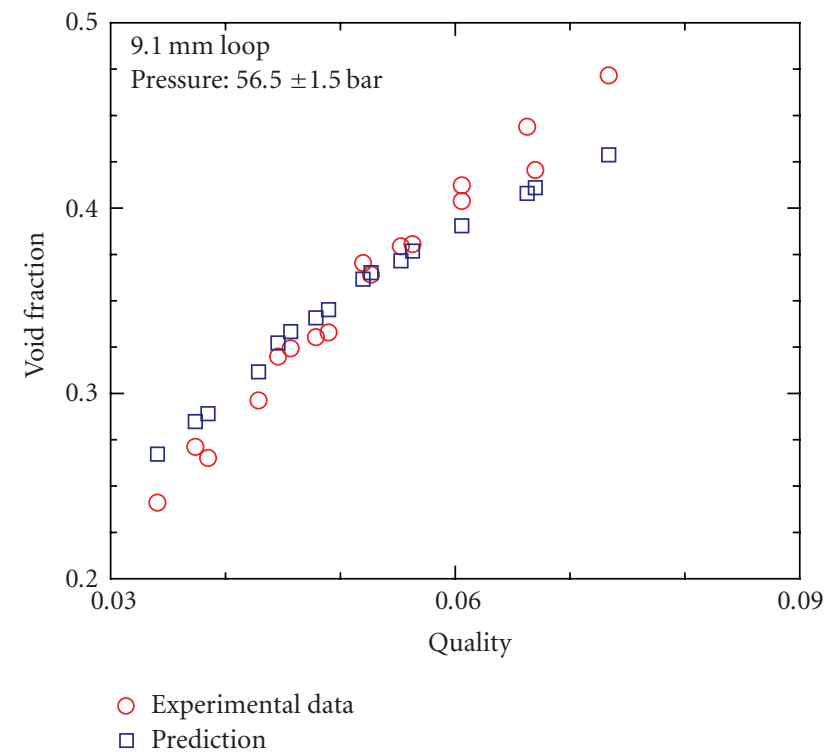

FIGURE 8: Comparison of measured void fraction with that predicted using Ishii model [31]

coefficients $\beta_{h}$ and $\beta_{T}$ valid for two-phase and single-phase flows, respectively, may be noted. The constants $C$ and $r$ have the same definitions as in single-phase flow. The measured steady state flow rate data from the present test loops are plotted in Figure 9 in dimensionless form. The data are found to be within $\pm 40 \%$ of the above theoretical correlation from Figure 9.

\subsection{Parametric effects on steady state flow}

One of the drawbacks of dimensionless correlations is that it often masks the parametric trends. In fact the steady state performance of two-phase loops is significantly influenced by the pressure, power, and loop diameter. Effect of pressure on two-phase NC flow was studied experimentally and theoretically in the $49.3 \mathrm{~mm}$ i.d. loop and the results are shown in Figure 10. The results are in agreement with the predictions of (7). The measured flow rate as a function of power is plotted in Figure 11 for various loops. The 


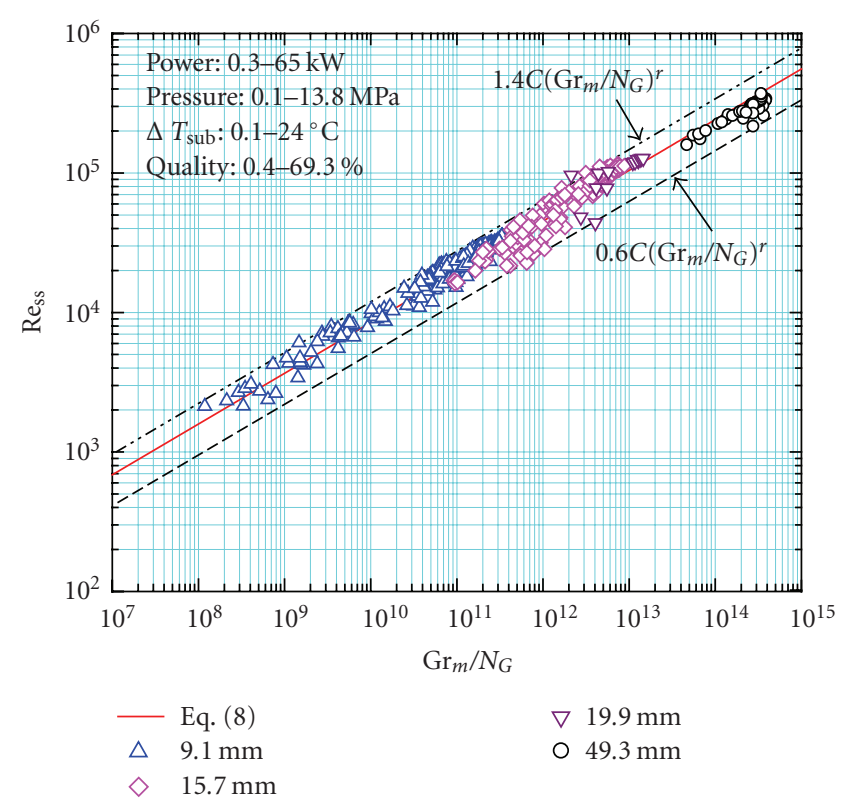

FIGURE 9: Comparison of steady state data with correlations.

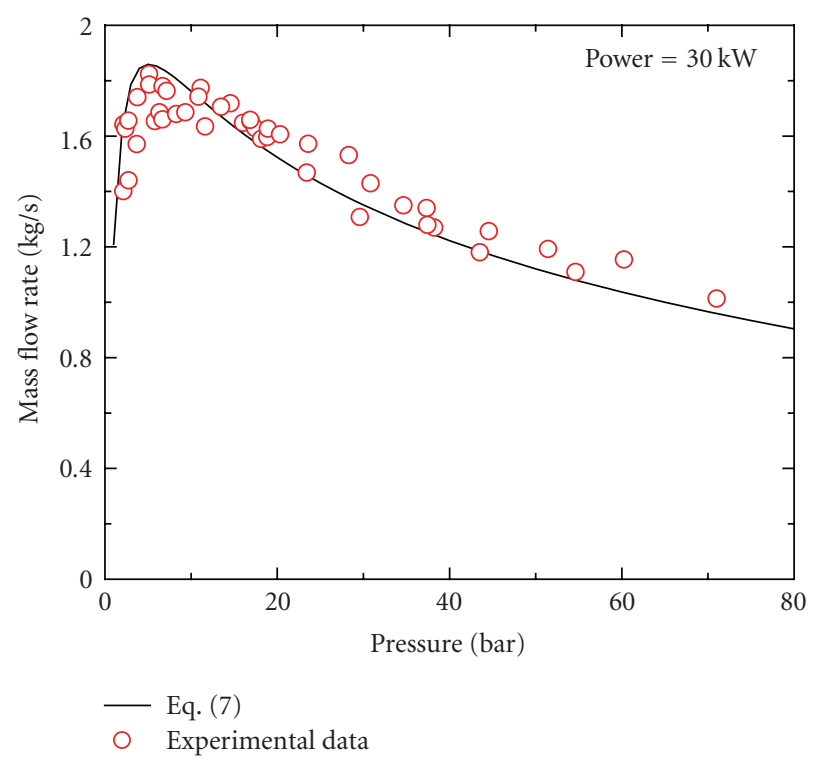

Figure 10: Effect of pressure on flow rate.

predictions with (7), TINFLO-S [34], and RELAP5/MOD3.2 are also given in Figure 11. Again, the data are in reasonable agreement with the predictions.

\subsection{Two-phase NC flow regimes}

Unlike single-phase natural circulation, it is observed that the trend of the steady state data can be significantly different for two-phase loops. Based on the nature of the variation of the steady state flow with power, three different natural circulation flow regimes can be observed for two-phase loops. These flow regimes are designated as gravity dominant, friction dominant, and the compensating regimes. In

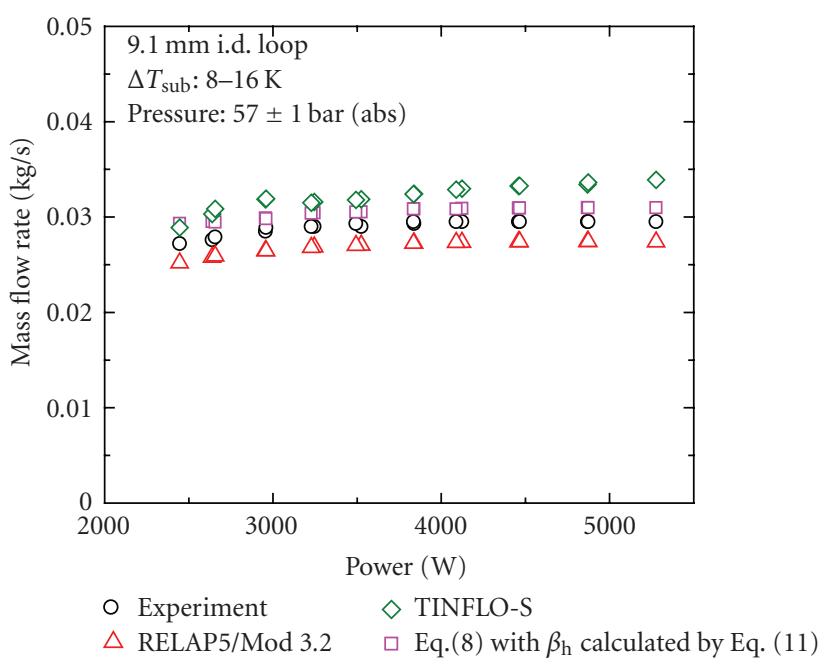

(a) $9.1 \mathrm{~mm}$ i.d. loop

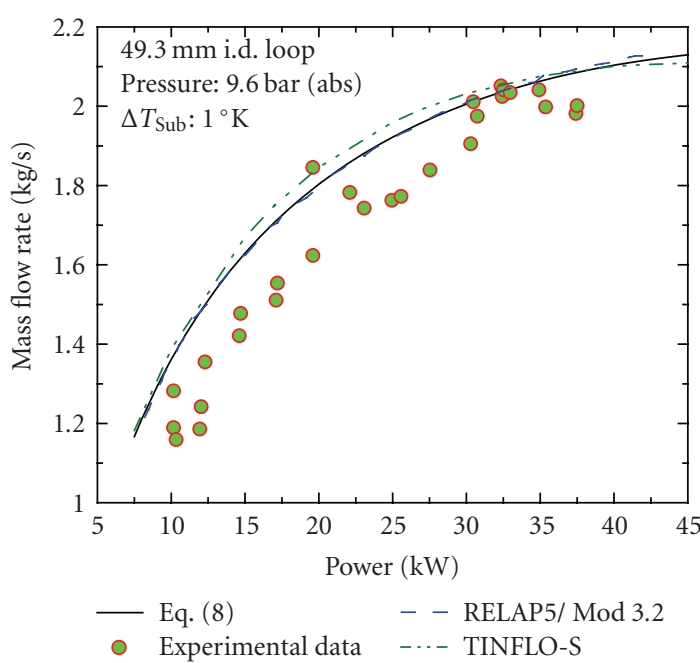

(b) $49.3 \mathrm{~mm}$ i.d. loop

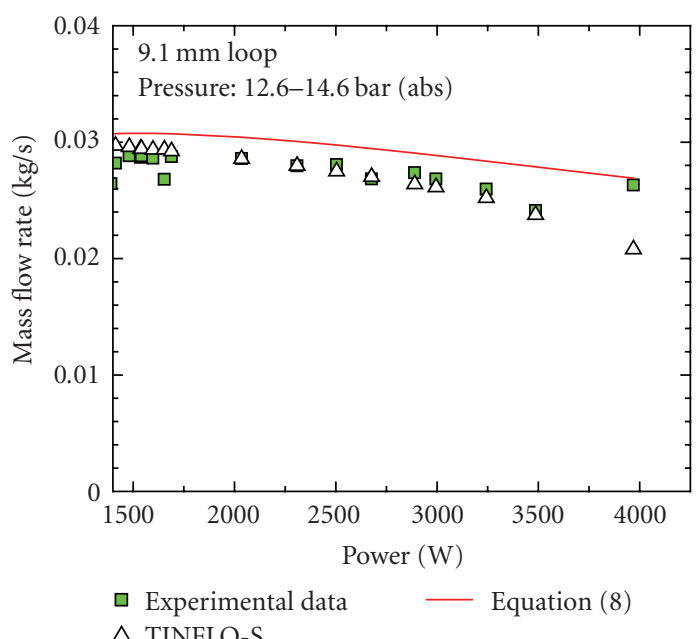

(c) $9.1 \mathrm{~mm}$ i.d. loop

FIGURE 11: Effect of power on the two-phase NC flow rate. 


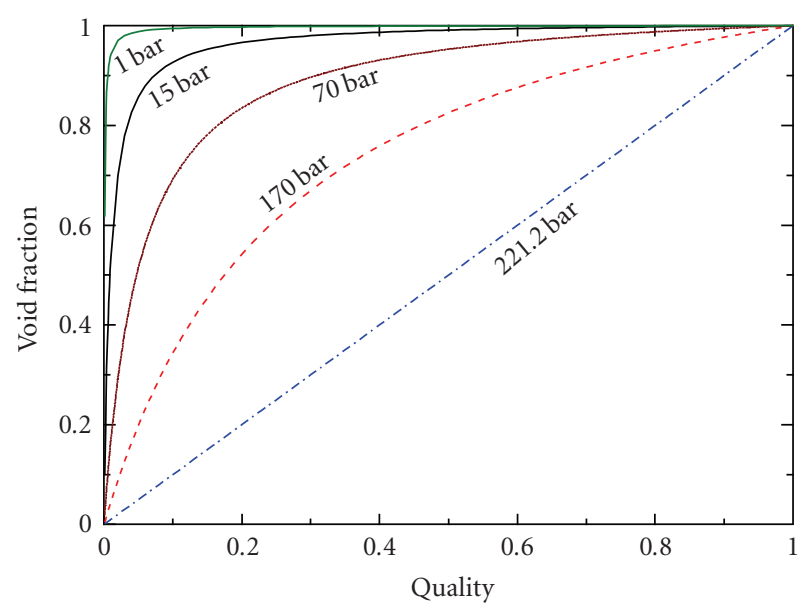

FIGURE 12: Effect of quality on void fraction.

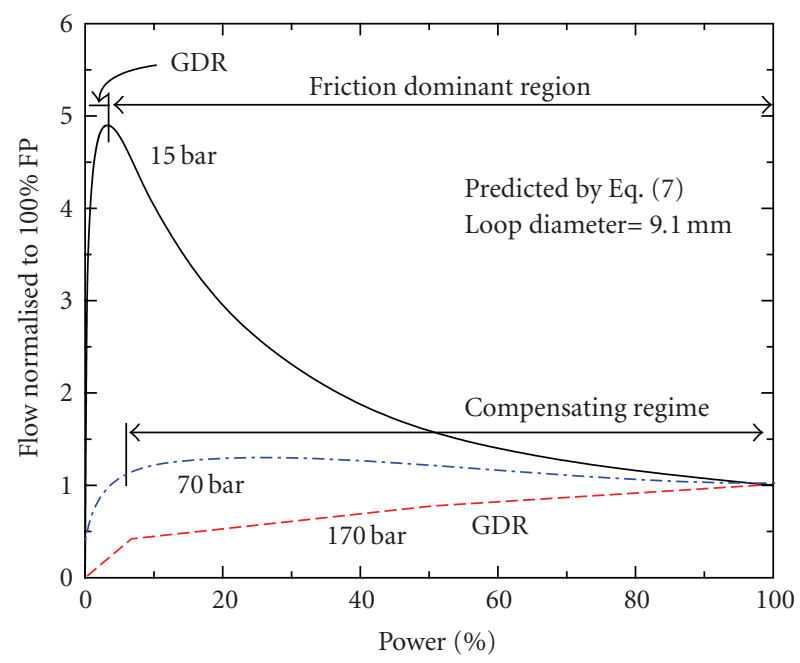

FIGURE 13: Effect of pressure on flow regime.

a natural circulation loop, the gravitational pressure drop (being the driving pressure differential) is always the largest component of pressure drop and all other pressure drops (friction, acceleration, and local) must balance the gravity (or buoyancy) pressure differential at steady state. However, the natural circulation flow regimes are differentiated based on the change of the pressure drop components with quality (or power).

\subsubsection{Gravity dominant regime}

The gravity dominant regime is usually observed at low qualities. In this regime, for a small change in quality there is a large change in the void fraction (see Figure 12) and hence the density and buoyancy force. The increased buoyancy driving force is to be balanced by a corresponding increase in the retarding frictional force that is possible only at a higher flow rate. As a result, the gravity dominant regime is characterized by an increase in the flow rate with power (see Figures 13 and 14).

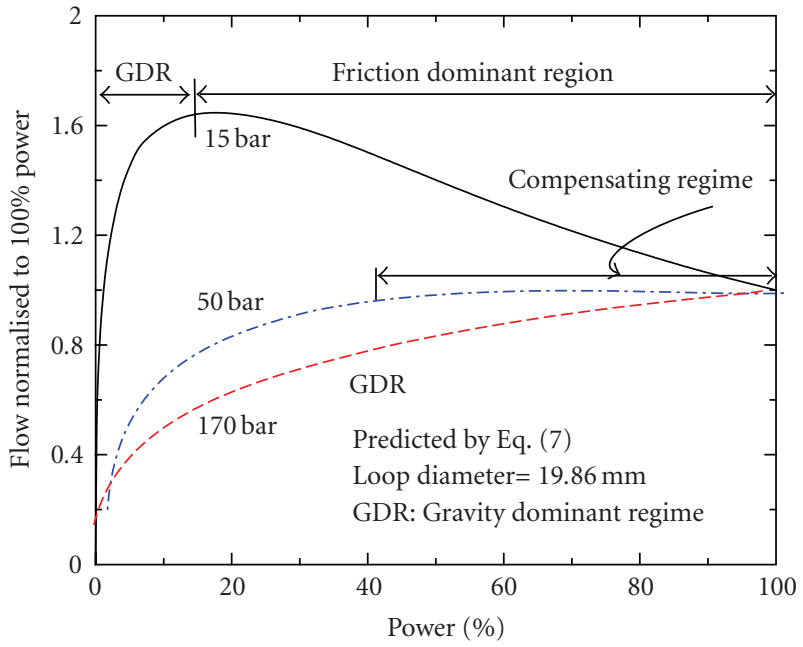

(a)

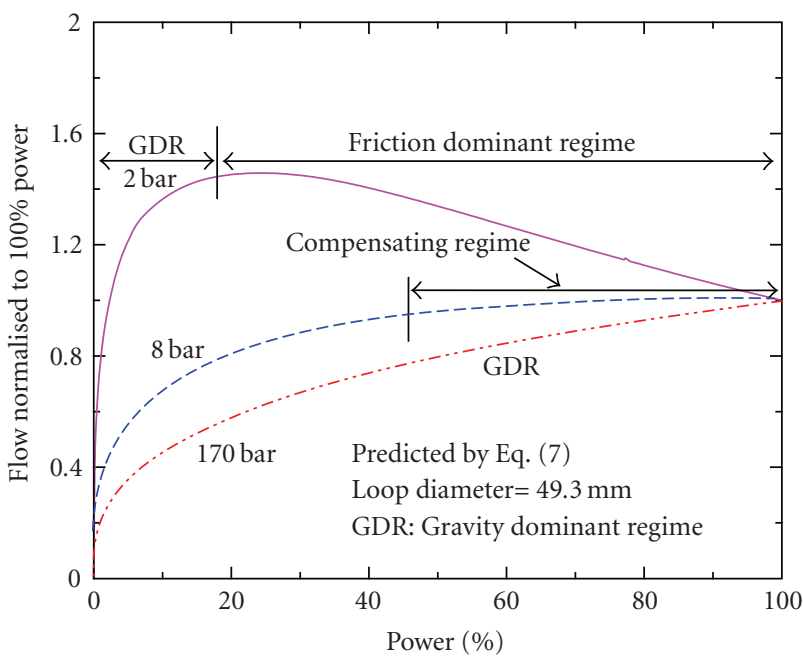

(b)

FIGURE 14: Effect of pressure on flow regime for different loop diameter.

\subsubsection{Friction dominant regime}

Friction dominant regime is observed at low to moderate pressures when quality is high. At higher qualities and moderate pressures, the increase in void fraction with quality is marginal (Figure 12) leading to almost constant buoyancy force. However, the continued conversion of high density water to low density steam due to increase in power requires that the mixture velocity must increase resulting in an increase in the frictional force and hence a decrease in flow rate. Thus, the friction dominant regime is characterized by a decrease in flow rate with increase in power (see the curve for 15 bar in Figure 13).

\subsubsection{Compensating regime}

Between the gravity dominant and friction dominant regimes, there exists a compensating regime, where the flow rate remains practically unaffected with increase in power. In 


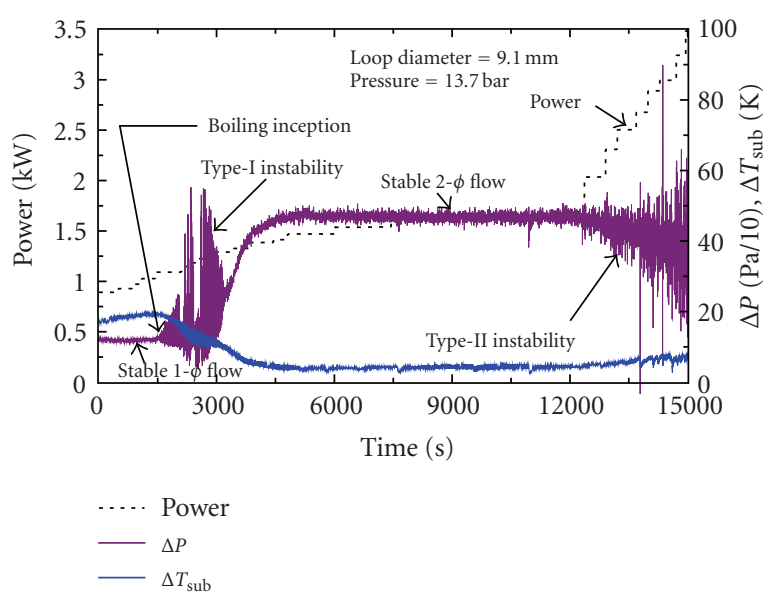

(a) Experimental stability map

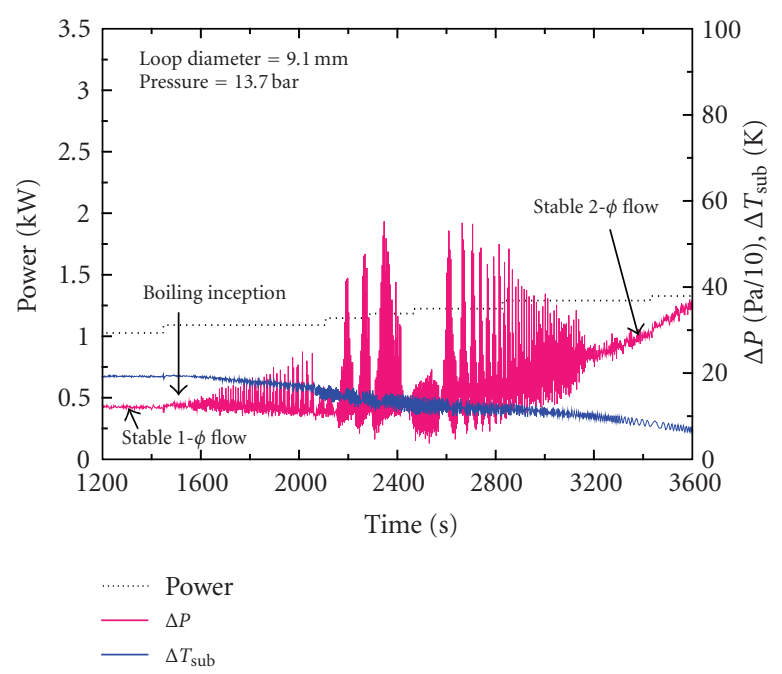

(b) Nature of type-I oscilation

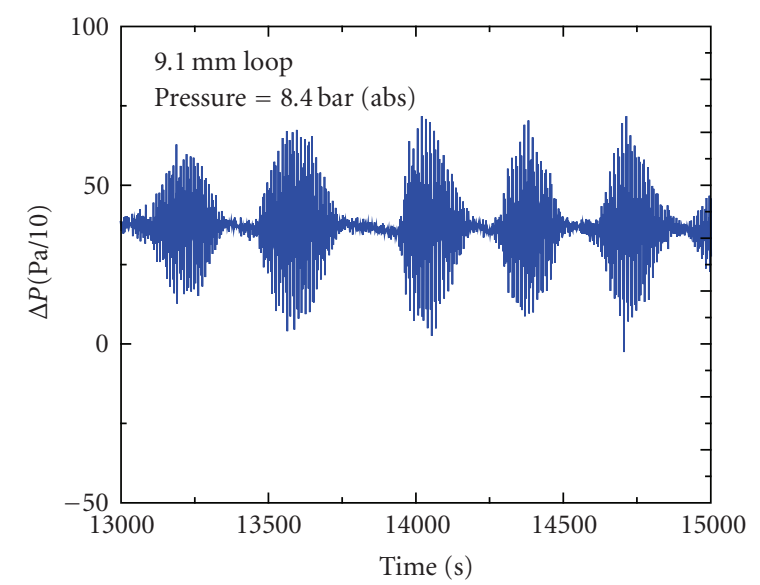

(c) Type-I oscilation

FIGURE 15: Experimental stability map and some typical type-I oscillation.

this regime, the increase in buoyancy force is compensated by a corresponding increase in the frictional force leaving the flow unaffected (see Figure 11(a) and the curve for $7 \mathrm{MPa}$ in Figure 13) in spite of increase in quality.

\subsubsection{Effect of pressure and loop diameter}

The NC flow regimes depend strongly on the system pressure. In fact, at high pressures only the gravity dominant regime (as in single-phase natural circulation) may be observed if the power is low. The friction dominant regime shifts to low pressures with increase in loop diameter (see Figure 14). Knowledge of the flow regimes is important to understand the stability behavior of two-phase loops.

\subsection{Stability behavior}

Two-phase natural circulation systems are susceptible to a large number of instabilities. Instability is undesirable as sustained flow oscillations may cause forced mechanical vibration of components. Further, premature critical heat flux (CHF) occurrence can be induced by flow oscillations as well as other undesirable secondary effects like power oscillations in BWRs. Instability can also disturb control systems and pose operational problems in nuclear reactors. The instabilities are broadly classified into three groups: static, dynamic, and compound dynamic instabilities. A more detailed description of natural circulation instabilities can be seen in [23].

\subsubsection{Experimental stability map}

An experimentally generated stability map for the $9.1 \mathrm{~mm}$ i.d. loop is shown in Figure 15(a), which shows two unstable regions for two-phase natural circulation. It may be noted that all the two-phase loops tested had stable single-phase natural circulation flow. However, it appears possible to get an unstable zone in the single-phase region also for certain loop geometries. Thus overall, three unstable zones (one in the single-phase region and two in the two-phase region) are possible for natural circulation loops with increase in power (excluding the single-phase vapour region). The first unstable zone in the two-phase region (Figure 15(a)) occurs at a low power and hence at low quality and is named as type I instability by Fukuda and Kobori [35]. Similarly, the second unstable zone in the two-phase region (Figure 15(a)) occurs at high powers and hence at high qualities and is named as type II instability. Theoretical analysis by the same authors has shown that the gravitational pressure drop plays a dominant role in type I instability where as frictional pressure drop is dominant in type II instability. In other words, type-I instability occurs in the gravity dominant regime whereas type-II instability occurs in the friction dominant regime. Instability is not found in the compensating regime during the present tests.

\subsubsection{Parametric effects on DWI}

Both type-I and type-II instabilities are affected by a large number of parameters out of which the effects of power, pressure, and loop diameter are studied both experimentally and theoretically in the present work. 


\subsubsection{Characteristics of type-I instability}

A general characteristic of type-I instability is that it occurs right from boiling inception. Flashing and geysering induced instability also belong to this category. Broadly speaking, the amplitude of type-I oscillations first increases, reaches a peak and then decreases with increase in power eventually leading to stable flow (Figure 15(b)). However, amplitude variation is a complex function of power presumably due to flow pattern transitions (Figure 15(b)). For certain type1 unstable regions, the flow alternates between a stable and oscillatory regime (Figure 15(c)). For large diameter loops, a unidirectional oscillation depicting a bean shaped limit cycle is observed (Figure 16). However, the dynamics is quite rich showing many different oscillatory patterns (see Figures 15(c), 16(a), and 16(c) for a few sample patterns).

The amplitude of type-I oscillations reduces significantly with increase in pressure (see Figures 15(a) and 17(a)). Further, type-I instability is not observed beyond a critical value of the system pressure (Figure 17(c)). While experimenting with uniform diameter loops, it was observed that the critical value of pressure beyond which the instability disappears is found to decrease with increase in the loop diameter (Figure 18). However, beyond a certain diameter, the effect of loop diameter on the critical pressure is found to be marginal.

\subsubsection{Characteristics of type-II instability}

In the present experiments, type-II instability (Figure 19) is found to occur after the flow starts to decrease with increase in power (characteristic of friction dominant regime). The threshold of type-II instability is found to increase with pressure as well as loop diameter. Type-II instability is observed in large diameter loops only at low pressures. A general characteristic of the type-II instability is that the oscillation amplitude keeps increasing monotonically with power. When the amplitude reaches a critical value, $\mathrm{CHF}$ occurs causing test section burnout. Burnout of the test section occurred frequently in the $7 \mathrm{~mm}$ loop and less frequently in the $9.1 \mathrm{~mm}$ loop.

\subsection{Theoretical results}

The stability of the test loops was studied with a linear stability code TINFLO-S based on the drift flux model (Nayak et al. [36]). The drift flux parameters $\left(C_{o}\right.$ and $V_{g i}$ ) for slug flow were used as it was the most frequently observed flow pattern during the tests. The MartinelliNelson two-phase friction multiplier model was used in the computations. Figures 20(a) and 20(b) compare the predicted stability map with experimental data. Figure 21(a) reveals that the stability is enhanced by increasing the loop diameter which is consistent with the test results. The effect of loop diameter on the lower threshold of instability (typeI instability) is less significant compared to that on the upper threshold (type-II instability). However, when plotted in terms of power (Figure 21(b)) both the lower and upper thresholds are found to be significantly influenced by the

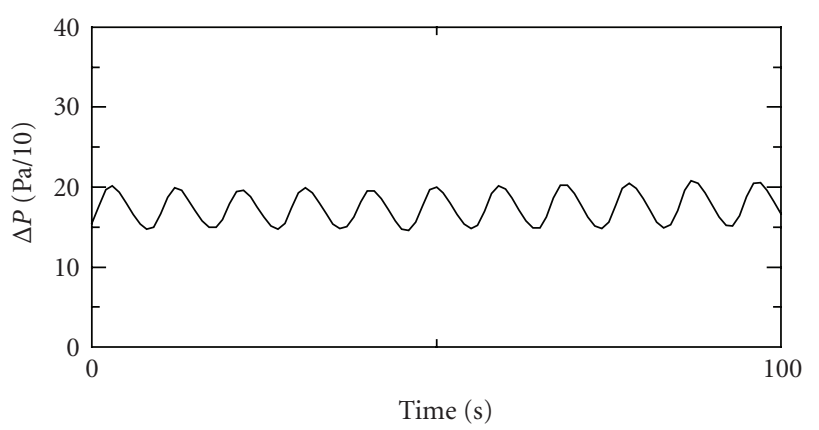

(a) Power $=20 \mathrm{~kW}$

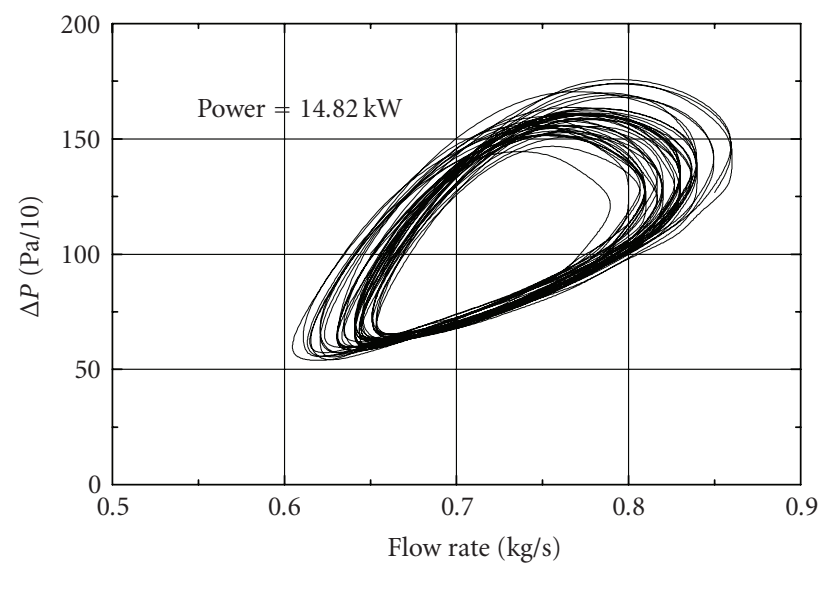

$-\Delta P$ across $1-\phi$ region

(b) Limit cycle at 2.2 bar

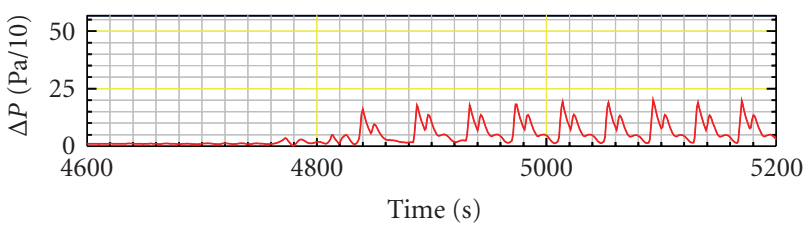

(c) Typical oscillations

FIGURE 16: Some typical type-1 oscillations and the limit cycle for observed for $49.3 \mathrm{~mm}$ i.d. loop.

loop diameter. Increase in inlet subcooling destabilizes typeI instability irrespective of the loop diameter. For type-II instability, however, similar behavior is observed only at low loop diameter. For large loop diameters, (see the stability map for $25 \mathrm{~mm}$ ) type-II instability stabilizes initially and then destabilizes. Similar behavior is also reported by Boure et al. [37].

\section{DESIGN CONSIDERATIONS}

The above results are significant to the design of the pressure tube type BWRs. For example, the experiments show that it is possible to avoid type-I instability by a pressurized startup (Figure 17). Figure 21(a) shows that the type-II instability threshold shifts to higher qualities with increase in loop diameter. For $40 \mathrm{~mm}$ loop diameter, the upper threshold is not found in the two-phase region (i.e., $0<$ quality $\leq 1$ ). Thus, by the appropriate choice of the loop diameter, it 


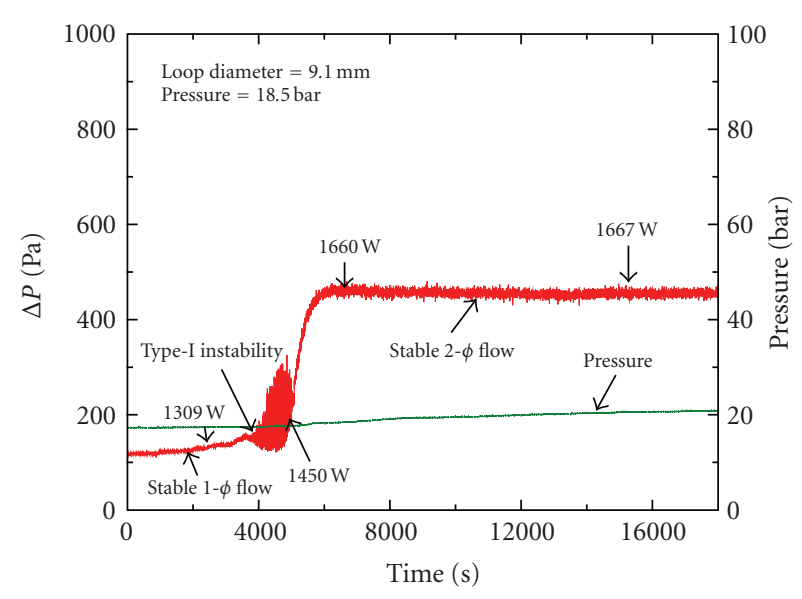

(a)

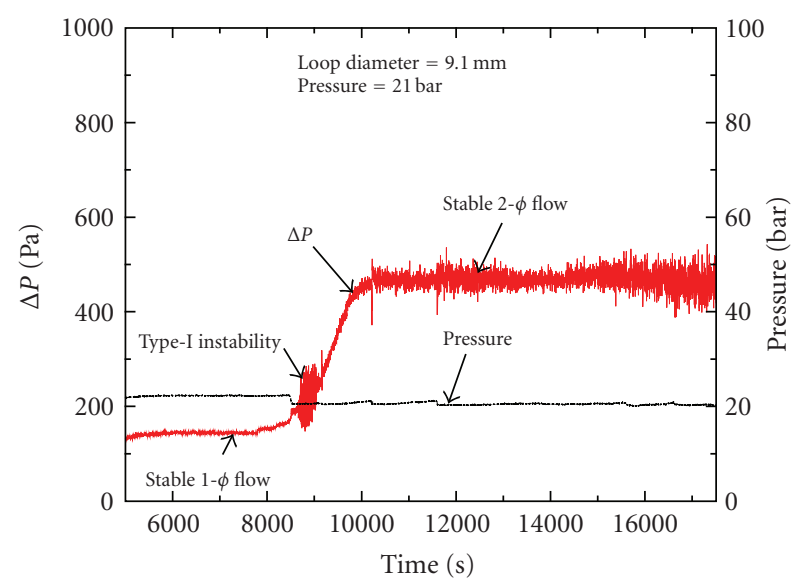

(b)

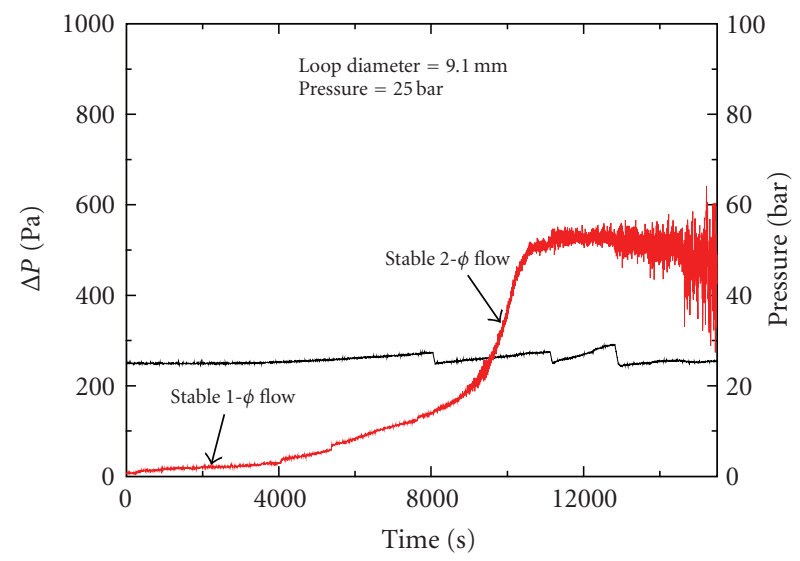

(c)

FIGURE 17: Effect of pressure on the type-I instability in the $9.1 \mathrm{~mm}$ inside diameter loop.

is possible to entirely eliminate the type-II instability in the two-phase loops. However, this is yet to be established experimentally as the maximum test section power was limited to $40 \mathrm{~kW}$. Experiments by Mochizuki [38] indicate that this instability occurs when the quality is close to unity at high pressure and large inlet subcooling. It may be

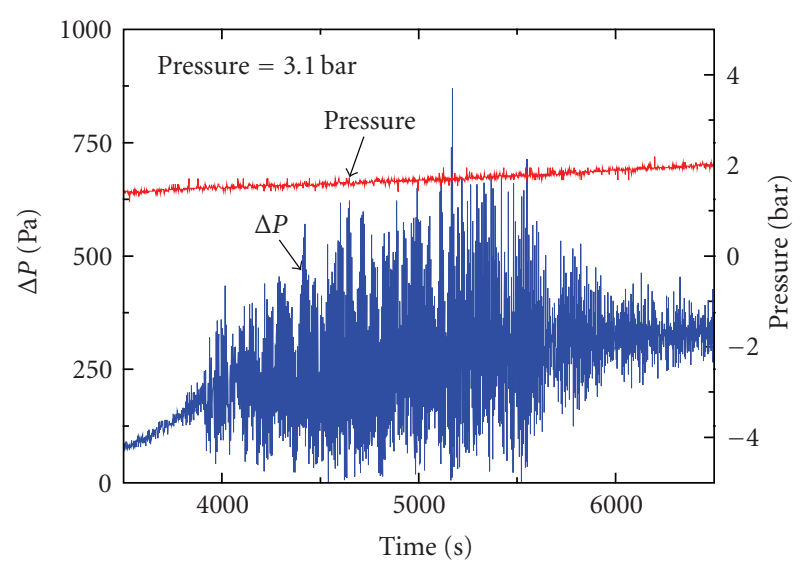

(a) Start-up at 3.1 bar

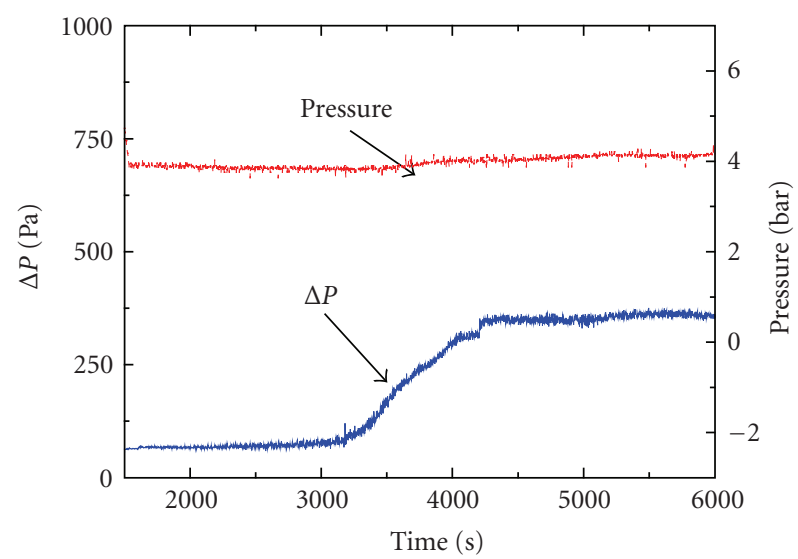

(b) Start-up at 5.4 bar

FIgURE 18: Effect of pressure on the instability due to boiling inception in $19.86 \mathrm{~mm}$ i.d. loop.

noted that the stable zone (difference in power between the upper and lower thresholds) is very low for small diameter loops, whereas it is significantly large in large diameter loops (Figure 21(b)).

\subsection{Design types for NCSs}

Since both instability and CHF (critical heat flux) need to be avoided in the design of two-phase natural circulation systems, two types of designs are possible depending on which of them is limiting the maximum power that can be extracted. These are designated as stability-controlled and CHF-controlled designs.

\subsubsection{Stability-controlled design}

In this type of loops, the maximum power is limited by the stability, as the threshold of type-II instability is lower than the CHF threshold. Figure 22 shows that this is normally the case in small diameter loops. These predictions were obtained by incorporating the look-up table (Groeneveld et al. [39]) in the TINFLO-S code. The heat balance method was used for the CHF prediction. In 


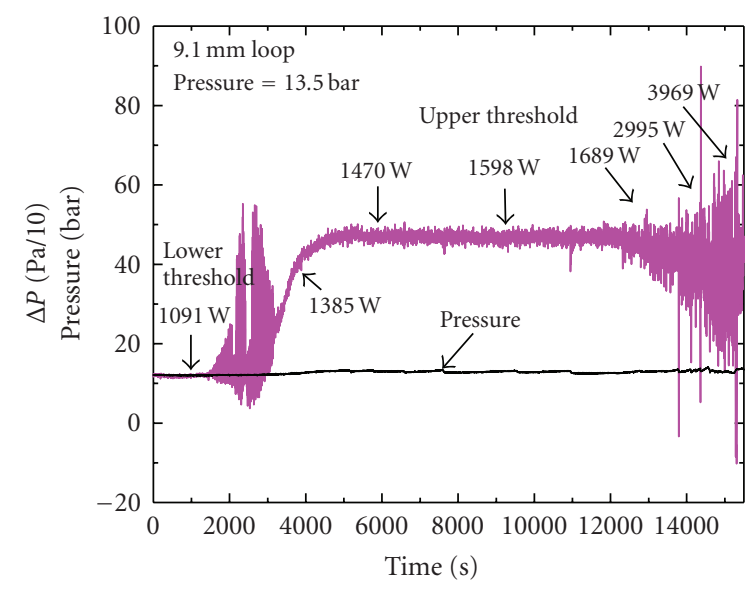

(a) 13 bar

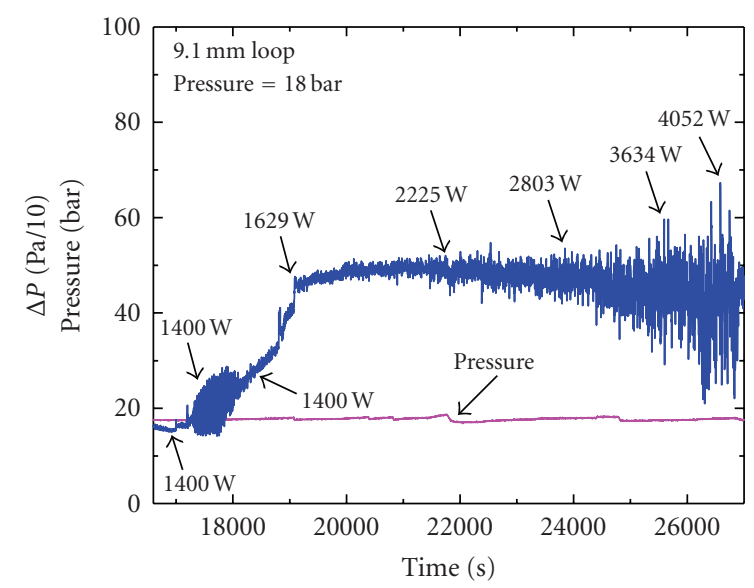

(b) $18 \mathrm{bar}$

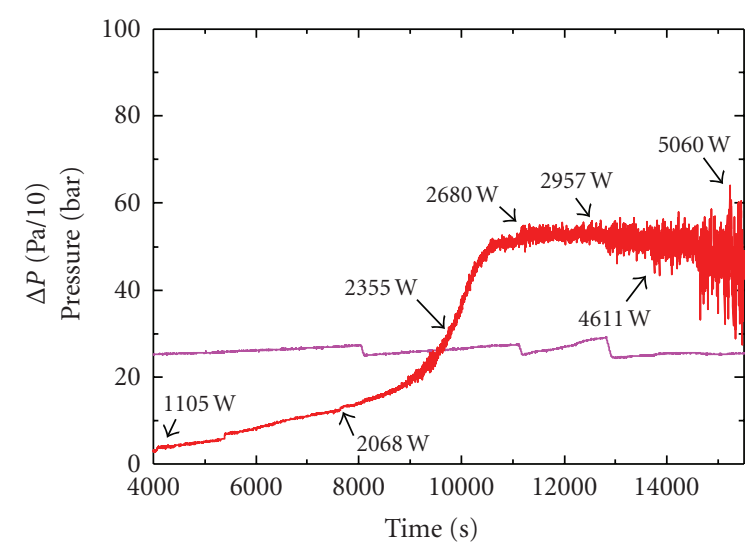

(c) $25 \mathrm{bar}$

FIgURE 19: The upper threshold of instability at different pressures.

Figure 22(c), stability-controlled design is found on the right of the dotted line.

\subsubsection{CHF-controlled design}

Characteristic of this design is that the CHF threshold is much below the type-II instability threshold and hence CHF limits the maximum power that can be extracted. Figure 23

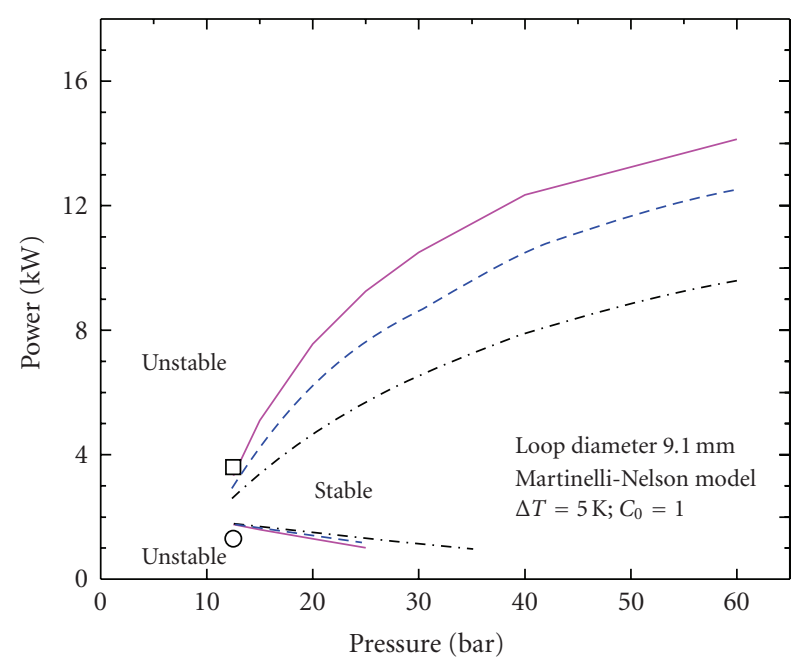

O Experimental threshold of type-I instability

$\square \quad$ Experimental threshold of type-II instability

-.-. $V_{g j}=0$

$--V_{g j}=0.1$

$V_{g j}=0.2$

(a) Effect of drift velocity

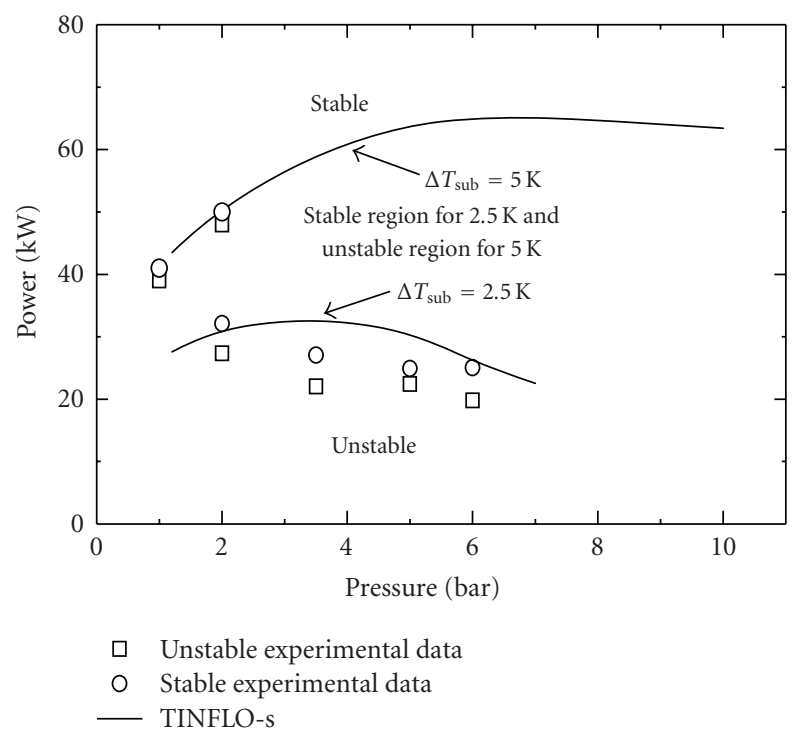

(b) Effect of subcooling

FIGURE 20: Comparison of measured and predicted stability maps.

shows that this situation arises in large diameter loops. In Figure 23(a), the design is CHF controlled only to the left of the vertical dotted line, while in Figures 23(b) and 23(c) the design is CHF controlled over the entire subcooling-power plane. Design of forced circulation BWRs is usually CHF controlled. By appropriate choice of the loop diameter, the design of an NCS can shift from stability controlled to CHF controlled (Figures 22 and 23).

\subsubsection{Operating line for stability-controlled designs}

Two-phase NCSs are not completely stable over the entire subcooling-power map and an operating line needs to be 


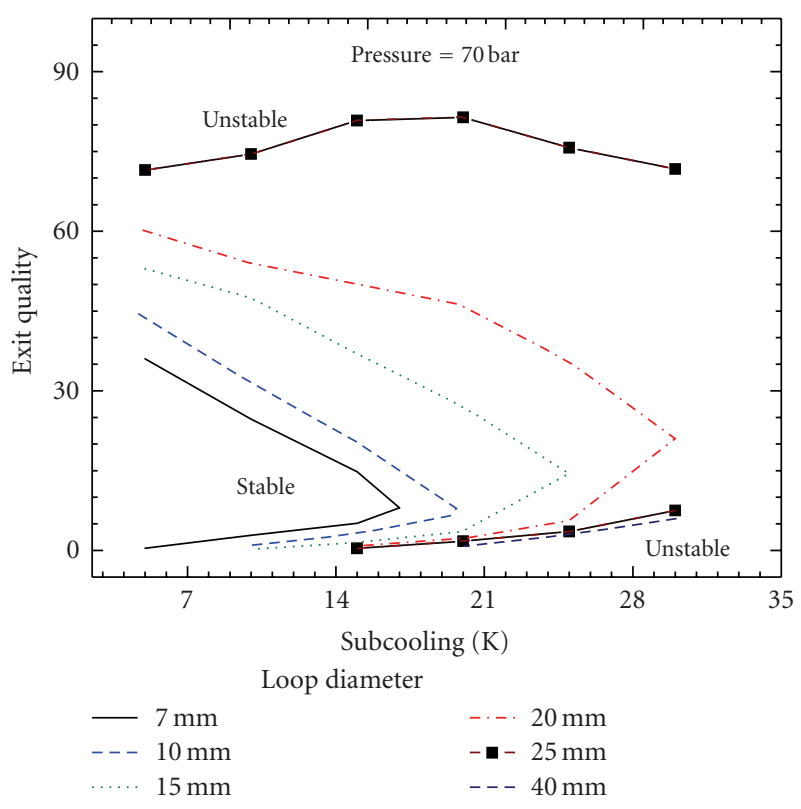

(a)

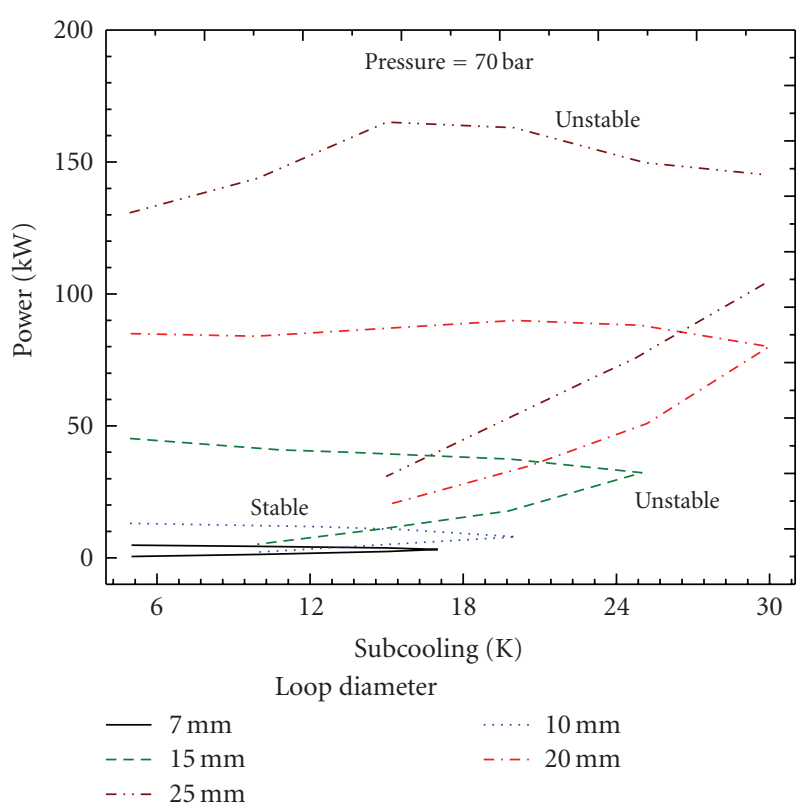

(b)

FIGURE 21: Predicted stability map for various loop diameters.

specified for ensuring stability for all anticipated operations like start-up, power raising, and step back. One would expect the decay ratio to go through a minimum while moving from the lower to the upper threshold for a fixed subcooling (Figure 24). Ideally, the operating line shall pass through the minimum decay ratio line (locus of all minimum decay ratio points (see also Figure 24)) so that all oscillations will die down in the quickest possible manner. In stabilitycontrolled designs, one could choose the operating line as the minimum decay ratio line if found feasible from feed water inlet temperature considerations (see also Vijayan et al. [40]).

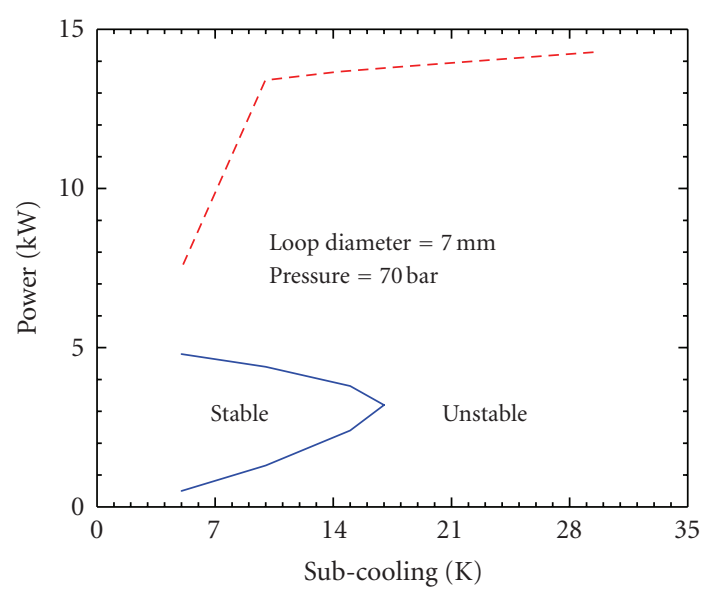

(a)

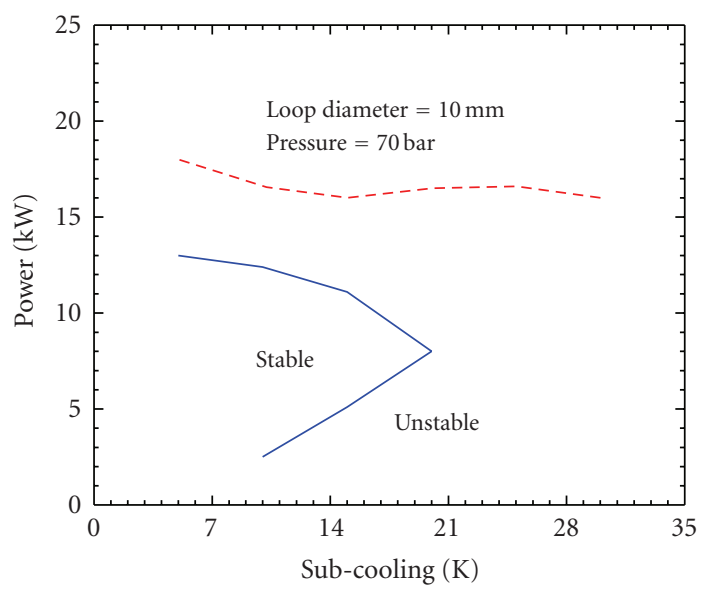

(b)

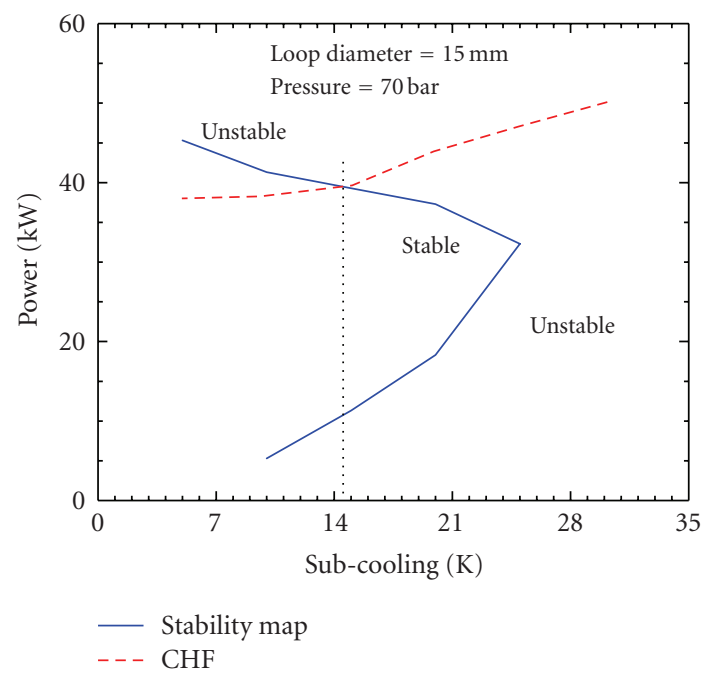

(c)

Figure 22: Stability controlled designs and loop diameter.

\subsubsection{Unstable oscillations and CHF}

Premature occurrence of $\mathrm{CHF}$ and test section burnout can be an issue during oscillatory flows in two-phase loops. In the present experiments, premature $\mathrm{CHF}$ occurrence was 
observed only at low pressures when the amplitude of flow oscillation is large. Although Figures 22(a) and 22(b) show that the CHF threshold is significantly higher than the instability threshold, burnout occurred only for the test section diameters of 7 and $9.1 \mathrm{~mm}$ in the present experiments. The occurrence of burnout during instability was more frequent in $7 \mathrm{~mm}$ diameter loop than in $9.1 \mathrm{~mm}$ loop. A typical observed temperature excursion following the occurrence of $\mathrm{CHF}$ in the $7 \mathrm{~mm}$ diameter test section is shown in Figure 25(a), where a heater trip based on high heater surface temperature terminated the transient. However, occurrence of CHF away from the thermocouple locations resulted in the burnout of the test section. Inspection of the burntout test sections revealed that the burnout is not restricted to the test section outlet. Premature occurrence of $\mathrm{CHF}$ was studied using RELAP5/MOD3.2 code for sinusoidal fluctuations in flow rate. The effect of amplitude and frequency was also studied for the $9.1 \mathrm{~mm}$ i.d. test section. Figure 25(b) shows that premature occurrence of CHF is a concern at low frequencies and high amplitudes.

\section{CONCLUDING REMARKS}

Effect of loop diameter was studied for both single-phase and two-phase natural circulation loops.

\section{Single-phase loops}

Four single-phase loops differing in diameter were studied. Instability was observed only in the two large diameter loops. The instability threshold is found to decrease with increase in loop diameter. Also, the threshold of instability is not a unique value as it depends on the operating procedure (hysteresis phenomenon). Linear analysis showed that the unstable region shifts up with decrease in loop diameter. Thus, small diameter loops are more stable than large diameter loops.

\section{Two-phase loops}

The steady state and stability behaviour of five loops differing in diameter were studied. Besides, the well known gravity and friction dominant regimes a compensating regime, where the flow is practically invariant with power is also observed under steady state. Both type-I and type-II instabilities are observed in small diameter loops, whereas only typeI instability was observed in large diameter loops. Type-I instability can be avoided by a pressurized start-up. However, the pressure beyond which the type-I instability disappears is found to decrease with increase in the loop diameter. Contrary to the observations in single-phase loops, the stability of two-phase loops is found to enhance with increase in loop diameter. Linear analysis showed that increase in subcooling destabilized type-I instability irrespective of loop diameter whereas type-II instability is found to destabilize for small diameter loops. For large diameter loops, typeII instability stabilizes initially with increase in subcooling and then destabilizes with further increase in subcooling. Stability analysis also revealed that the type-II instability

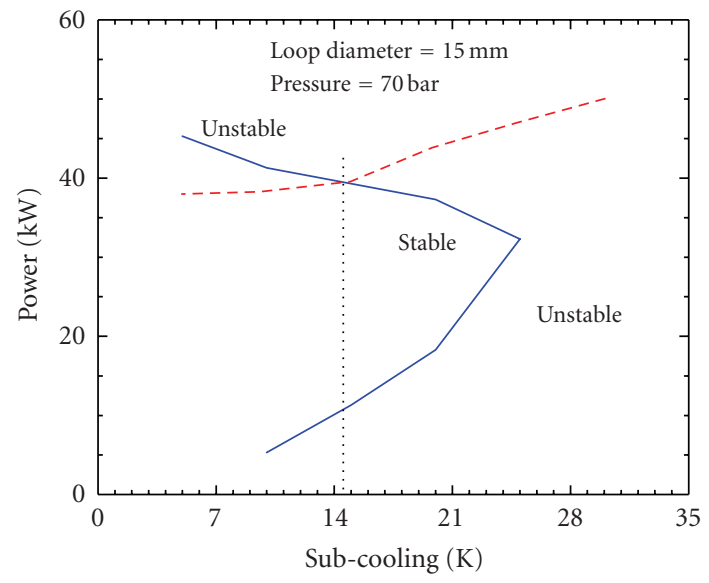

(a)

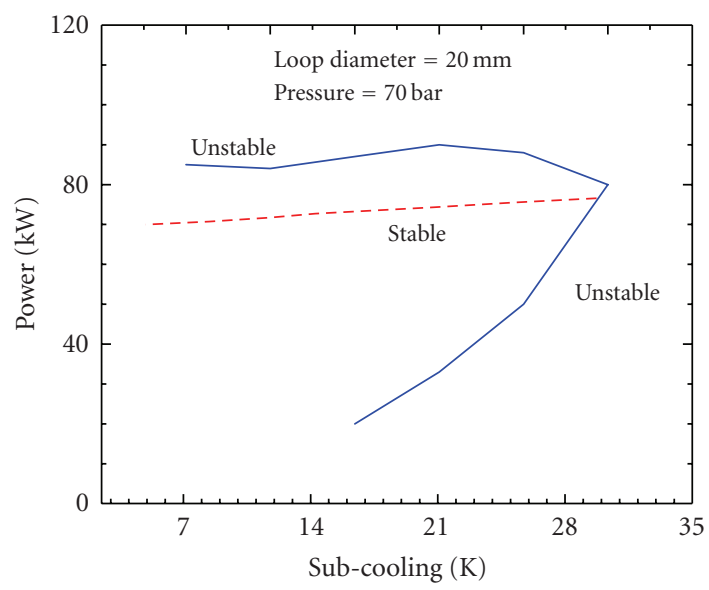

(b)

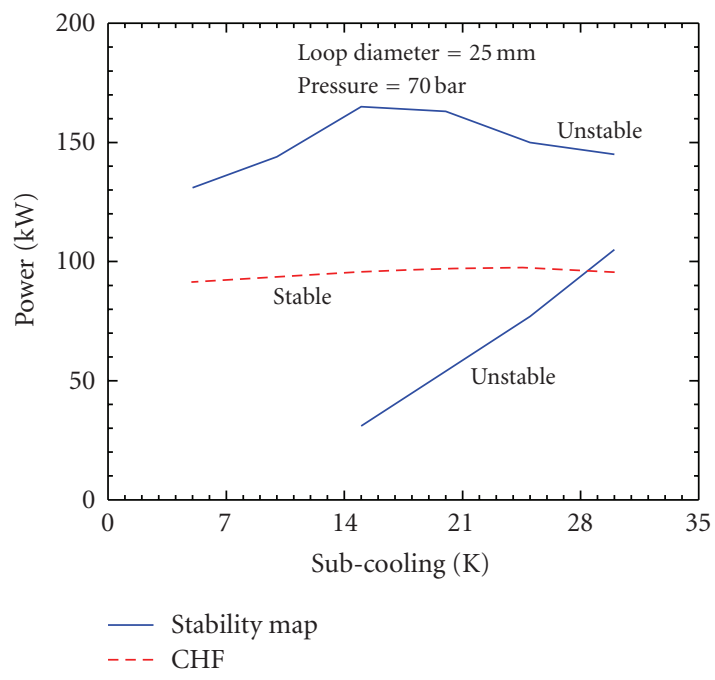

(c)

FIgURE 23: CHF controlled designs and loop diameter.

is not observable in the two-phase region $(0<\mathrm{x}<1)$ for large diameter loops at moderate pressures (70 bar). Premature occurrence of $\mathrm{CHF}$ and burnout is a serious problem at low-frequency high-amplitude oscillatory flow in small diameter loops. The study also shows that the 


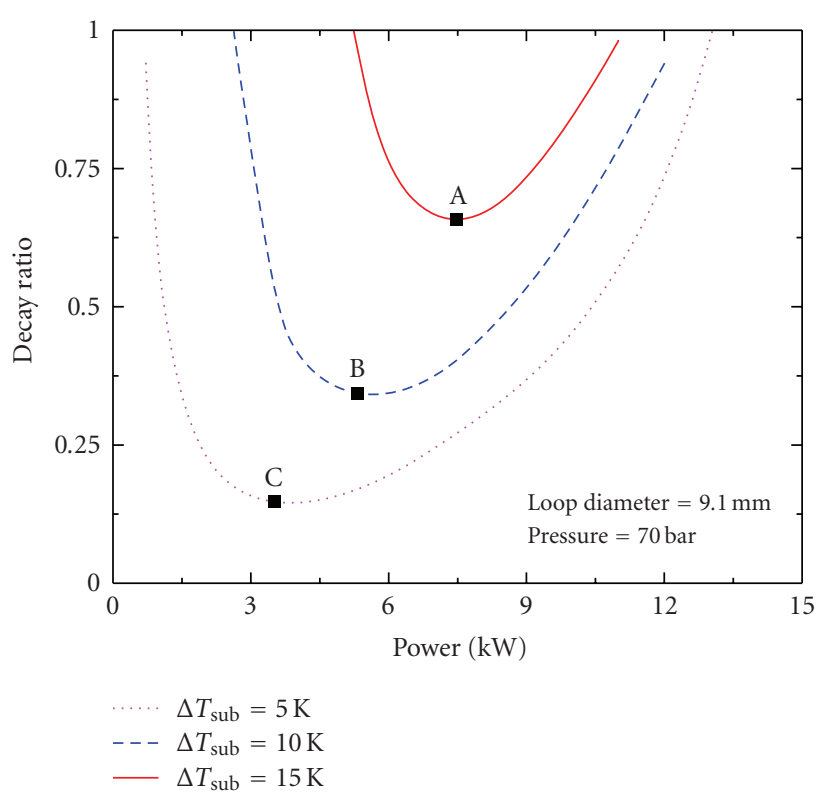

FIgURE 24: Variation of decay ratio (DR).

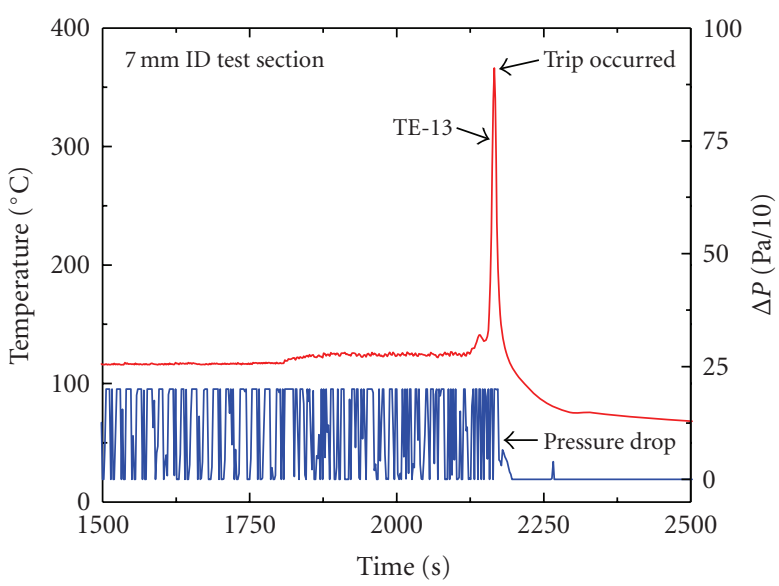

(a) Premature CHF occurrence

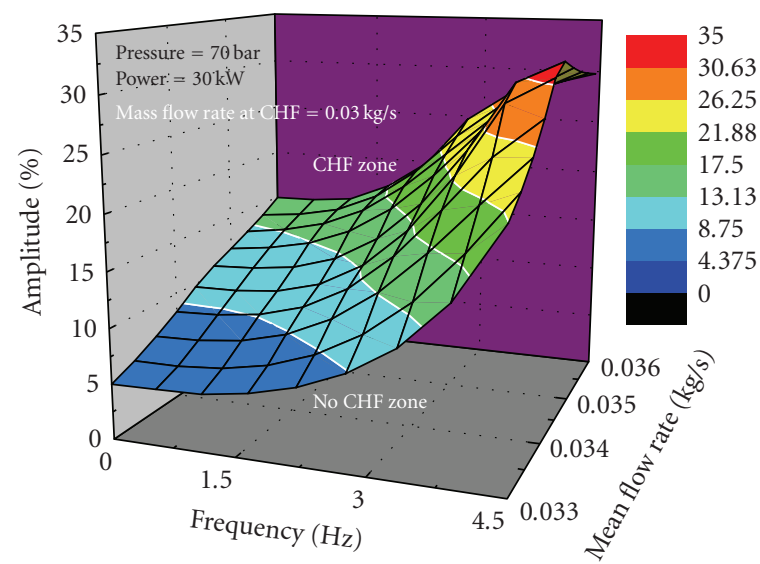

(b) Effect of amplitude and frequency

FIGURE 25: Premature CHF occurrence with oscillatory flow. maximum operating power of NCSs can be CHF controlled or instability controlled depending on the loop diameter. For stability controlled designs, the minimum decay ratio (DR) line could be a feasible operating line.

\section{NOMENCLATURE}

A: $\quad$ Flow area, $\mathrm{m}^{2}$

$b$ Exponent in the friction factor equation

$C p:$ Specific heat, $\mathrm{J} /(\mathrm{kg} \mathrm{K})$

D: Hydraulic diameter, $\mathrm{m}$

$f$ : $\quad$ Darcy-Weisbach friction factor

$g$ : Gravitational acceleration, $\mathrm{m} / \mathrm{s}^{2}$

$\mathrm{Gr}_{m}$ : Modified Grashof number

$h$ : Enthalpy, J/kg

l: $\quad$ Dimensionless length, $L_{i} / L_{t}$

L: $\quad$ Length, $\mathrm{m}$

$L_{x}$ : Length of adiabatic horizontal section (see Figure 1(a)), m

$p$ : Constant in the friction factor equation

$P$ : Pressure, $\mathrm{Pa}$

$Q_{h}:$ Total heat input rate, W

$v$ : Specific volume, $\mathrm{m}^{3} / \mathrm{kg}$

$S t_{m}$ : Modified Stanton number

$W: \quad$ Mass flow rate, $\mathrm{kg} / \mathrm{s}$

$x: \quad$ Quality

$Z$ : Dimensionless elevation

$\Delta z$ : Center line elevation difference, $\mathrm{m}$.

\section{GREEK SYMBOLS}

$\alpha$ : Void fraction

$\beta$ : $\quad$ Thermal expansion coefficient, $\mathrm{K}^{-1}$

$\phi: \quad$ Dimensionless parameter, $\mathrm{AH} / L_{t}$

$\phi_{\mathrm{LO}}^{2}:$ Two-phase friction multiplier

$\bar{\phi}_{\mathrm{LO}}^{2}$ : Mean value of $\phi_{\mathrm{LO}}^{2}$

$\rho: \quad$ Density, $\mathrm{kg} / \mathrm{m}^{3}$

$\Delta \rho:$ Density difference across the heater, $\mathrm{kg} / \mathrm{m}^{3}$

$\Delta h$ : Enthalpy difference over the heater, J/kg

$\mu$ : Dynamic viscosity, Ns $/ \mathrm{m}^{2}$

$\theta$ : Dimensionless temperature.

\section{SUBSCRIPTS}

$B$ : Boiling length

c: Cooler

cl: Cold leg

e: Heater exit

eff: Effective

g: Vapor

h: Heater

hl: Hot leg

$i$ : ith segment

in: Heater inlet

l: Liquid

$m$ : Mean

sp: Single phase

ss: Steady state

$t$ : Total

tp: Two-phase. 


\section{REFERENCES}

[1] O. B. Samoilov and A. V. Kurachenkov, "Nuclear district heating plants AST-500. Present status and prospects for future in Russia," Nuclear Engineering and Design, vol. 173, no. 1-3, pp. 109-117, 1997.

[2] D. F. Delmastro, "Thermal-hydraulic aspects of CAREM reactor," in Proceeding of the IAEA Technical Committee Meeting on Natural Circulation Data and Innovative Nuclear Power Plant Design, Vienna, Austria, July 2000.

[3] R. K. Sinha and A. Kakodkar, "Requirements for the design of advanced heavy water reactor," in Proceedings of IAEA TCM Workshop on Requirements for the Next Generation of Water Cooled Reactor, Beijing, China, October 1990.

[4] Y. N. Kuznetsov, A. A. Romenkov, A. I. Alekseev, F. D. Lisitsa, Y. I. Tokarev, and O. A. Yarmolenko, "NPP with VK-300 boiling water reactor for power and district heating grids," in Proceedings of International Seminar on Small and Medium Sized Reactors: Status and Prospects, Organized by IAEA, Cairo, Egypt, May 2001, IAEA-SR-218/32.

[5] V. A. Silin, V. A. Voznesensky, and A. M. Afrov, "The light water integral reactor with natural circulation of the coolant at supercritical pressure B-500 SKDI," Nuclear Engineering and Design, vol. 144, no. 2, pp. 327-336, 1993.

[6] S. J. Bushby, G. R. Dimmick, R. B. Duffey, N. J. Spinks, K. A. Burrill, and P. S. W. Chan, "Conceptual designs for advanced, high-temperature CANDU reactors," in Proceedings of the Supercritical Water Reactors Symposium (SCR-2000), Tokyo, Japan, November 2000.

[7] Y. Zvirin, "A review of natural circulation loops in pressurised water reactors and other systems," Nuclear Engineering and Design, vol. 67, no. 2, pp. 203-225, 1981.

[8] R. Greif, "Natural circulation loops," Journal of Heat Transfer, vol. 110, pp. 1243-1258, 1988.

[9] G. Yadigaroglu, "Two-phase flow instabilities and propagation phenomena," in Thermohydraulics of Two-Phase Systems for Industrial Design and Nuclear Engineering, J. M. Delhaye, M. Giot, and M. L. Reithmuller, Eds., Hemisphere, Washington, DC, USA, 1978.

[10] S. Kakac, "Review of two-phase flow instabilities," Journal of Pure and Applied Sciences, vol. 18, pp. 171-252, 1985.

[11] P. K. Vijayan, M. H. Bade, D. Saha, R. K. Sinha, and V. Venkat Raj, "A generalized flow correlation for single-phase natural circulation loops," in Proceedings of the17th National and 6th ISHMT/ASME Heat and Mass Transfer Conference, Kalpakkam, India, January 2004, HMT-2004-C022.

[12] H. H. Bau and K. E. Torrance, "Transient and steady state behaviour of an open, symmetrically heated, free convection loop," International Journal of Heat and Mass Transfer, vol. 24, no. 4, pp. 597-609, 1981.

[13] C. J. Ho, S. P. Chiou, and C. S. Hu, "Heat transfer characteristics of a rectangular natural circulation loop containing water near its density extreme," International Journal of Heat and Mass Transfer, vol. 40, no. 15, pp. 3553-3558, 1997.

[14] J. P. Holman and J. H. Boggs, "Heat transfer to freon 12 near the critical state in a natural circulation loop," Journal of Heat Transfer, vol. 82, pp. 221-226, 1960.

[15] B. J. Huang and R. Zelaya, "Heat transfer behaviour of a rectangular thermosyphon loop," Journal of Heat Transfer, vol. 110, pp. 487-493, 1988.

[16] M. Misale, L. Tagliafico, and G. Tanda, "Experiments in a free convection rectangular loop," in Proceedings of the 4th
International Symposium on Transport Phenomena in Heat and Mass Transfer, pp. 203-211, Sydney, Australia, July 1991.

[17] T. Nishihara, "Oscillatory instability of a single-phase natural circulation loop," in Proceedings of the 8th International Topical Meeting on Nuclear Reactor Thermal-Hydraulics (NURETH '97), pp. 839-847, Kyoto, Japan, SeptemberOctober 1997.

[18] M. Misale, P. Garibaldi, J. C. Passos, and G. G. de Bitencourt, "Experiments in a single-phase natural circulation mini-loop," Experimental Thermal and Fluid Science, vol. 31, no. 8, pp. 1111-1120, 2007.

[19] S. K. Mousavian, M. Misale, F. D'Auria, and M. A. Salehi, "Transient and stability analysis in single-phase natural circulation," Annals of Nuclear Energy, vol. 31, no. 10, pp. 11771198, 2004.

[20] P. K. Vijayan, V. K. Bhojwani, M. H. Bade, et al., "Investigations on the effect of heater and cooler orientation on the steady state, transient and stability behaviour of single-phase natural circulation in a rectangular loop," 2001, BARC/2001/E/034.

[21] P. K. Vijayan, M. Sharma, D. S. Pilkhwal, et al., "Experimental and numerical investigations on the nature of the unstable oscillatory flow in a single phase natural circulation loop," in Proceedings of the 17th National and 6th ISHMT/ASME Heat and Mass Transfer Conference, Kalpakkam, India, January 2004, HMT-2004-C100.

[22] P. K. Vijayan, M. Sharma, and D. Saha, "Steady state and stability characteristics of single-phase natural circulation in a rectangular loop with different heater and cooler orientations," Experimental Thermal and Fluid Science, vol. 31, no. 8, pp. 925-945, 2007.

[23] P. K. Vijayan and A. K. Nayak, "Introduction to instabilities in natural circulation systems," in IAEA Course on Natural Circulation in Water-Cooled Nuclear Power Plants, ICTP, Trieste, Italy, June-July 2004.

[24] P. K. Vijayan, G. S. S. P. Rao, D. S. Bisht, S. P. Nalawade, D. Saha, and R. K. Sinha, "Side-by-side comparison of void fraction measured by neutron attenuation technique and electrical conductance probe," in Proceedings of the 17th National and 6th ISHMT/ASME Heat and Mass Transfer Conference, Kalpakkam, India, January 2004.

[25] P. Dubey, G. S. S. P. Rao, D. S. Pilkhwal, P. K. Vijayan, and D. Saha, "Analysis of experimental data on two-phase natural circulation from the flow pattern transition instability studies facility at Apsara reactor," 2004, BARC/2004/E/031, Bhabha Atomic Research Centre, Trombay, Mumbai, India.

[26] N. Kumar, R. Rajalakshmi, R. D. Kulkarni, T. V. Sagar, P. K. Vijayan, and D. Saha, "Experimental investigation in high pressure natural circulation loop,” 2000, BARC/2000/E/002, Bhabha Atomic Research Centre, Trombay, Mumbai, India.

[27] A. Sinha, P. K. Vijayan, and A. M. Shaikh, "Visualization and analysis of two phase flow by neutron radiography and its applications in the thermal hydraulic studies of advanced reactors," in Proceedings of the 6th World Conference on Neutron Radiography, Osaka, Japan, May 1999.

[28] A.E. Taitel, D. Bornea, and A. E. Dukler, "Modelling flow pattern transitions for steady upward gas-liquid flow in vertical tubes," AIChE Journal, vol. 26, no. 3, pp. 345-354, 1980.

[29] K. Mishima and M. Ishii, "Flow regime transition criteria for upward two-phase flow in vertical tubes," International Journal of Heat and Mass Transfer, vol. 27, no. 5, pp. 723-737, 1984. 
[30] C. W. Solbrig, "Consistent flow regime map and friction factors for two-phase flow," in Proceeding of the American Institute of Chemical Engineers Annual Meeting (AIChE '86), Miami Beach, Fla, USA, November 1986.

[31] M. Ishii,, "One-dimensional drift-flux model and constitutive equations for relative motion between phases in various twophase flow regimes," Tech. Rep. ANL-77-47, Argonne National Laboratory, Argonne, Ill, USA, 1977.

[32] G. S. S. P. Rao, P. K. Vijayan, D. Saha, P. S. Sarkar, A. Sinha, and B. K. Godwal, "Experimental investigations in two-phase natural circulation loops relevant to the AHWR Part-1: steady state behavior of two-phase natural circulation,” 2006, BARC/2006/E/003, Bhabha Atomic Research Centre, Trombay, Mumbai, India.

[33] M. R. Gartia, P. K. Vijayan, and D. S. Pilkhwal, "A generalized flow correlation for two-phase natural circulation loops," Nuclear Engineering and Design, vol. 236, no. 17, pp. 18001809, 2006.

[34] A. K. Nayak, N. Kumar, P. K. Vijayan, D. Saha, and R. K. Sinha, "Analytical study of flow instability behaviour of a boiling twophase natural circulation loop under low quality conditions," Kerntechnik, vol. 67, part 2-3, pp. 95-101, 2002.

[35] K. Fukuda and T. Kobori, "Classification of two-phase flow stability by density-wave oscillation model," Journal of Nuclear Science and Technology, vol. 16, pp. 95-108, 1979.

[36] A. K. Nayak, P. Dubey, D. N. Chavan, and P. K. Vijayan, "Study on the stability behavior of two-phase natural circulation systems using a four-equation drift flux model," in Proceedings of the 18th National \& 7th ISHMT-ASME Heat and Mass Transfer Conference, Guwahati, India, January 2006, HMT2006-C084.

[37] J. A. Boure, A. E. Bergles, and L. S. Tong, "Review of two-phase flow instability," Nuclear Engineering and Design, vol. 25, no. 2, pp. 165-192, 1973.

[38] H. Mochizuki, "Experimental and analytical studies of flow instabilities in pressure tube type heavy water reactors," Journal of Nuclear Science and Technology, vol. 29, no. 1, pp. 50-67, 1992.

[39] D. C. Groeneveld, L. K. H. Leung, P. L. Kirillov, et al., "The 1995 look-up table for critical heat flux in tubes," Nuclear Engineering and Design, vol. 163, no. 1-2, pp. 1-23, 1996.

[40] P. K. Vijayan, A. K. Nayak, G. S. S. P. Rao, R. K. Bagul, D. Saha, and R. K. Sinha, "Designing for stability in a natural circulation pressure tube type boiling water reactor," in Proceedings of the 11th International Topical Meeting on Nuclear Reactor Thermal-Hydraulics (NURETH '05), Avignon, France, October 2005. 

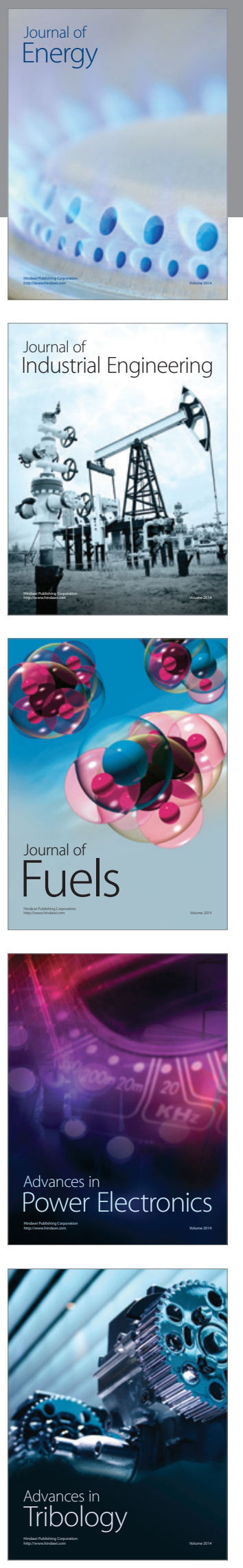
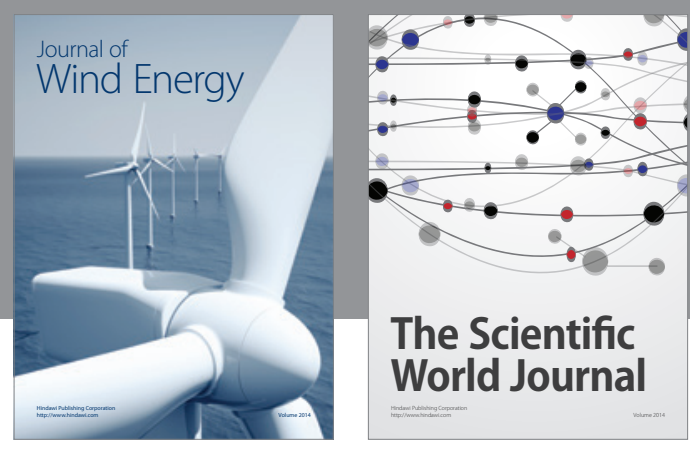

The Scientific World Journal

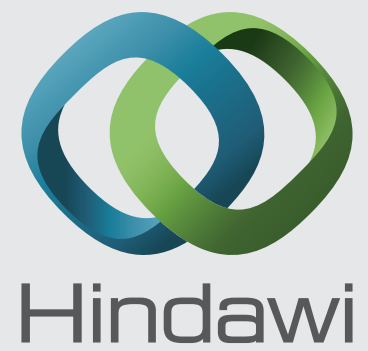

Submit your manuscripts at http://www.hindawi.com
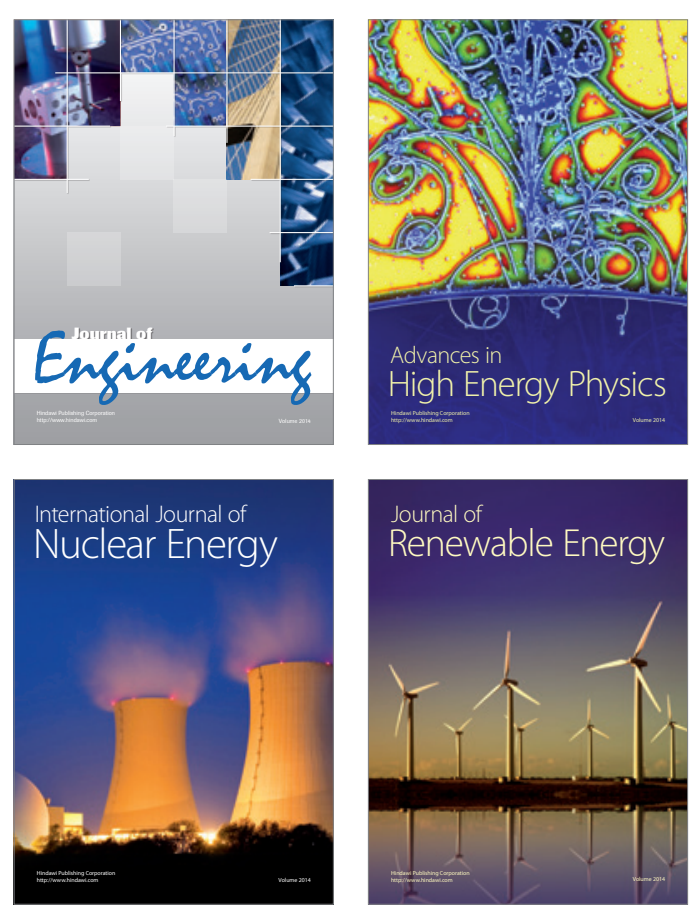

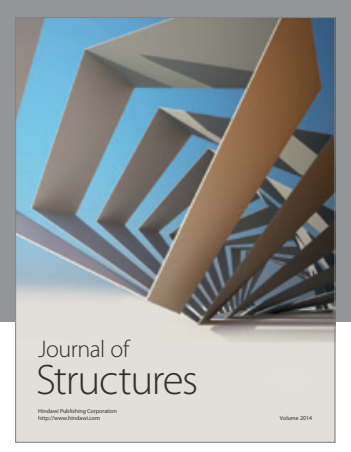

Rotating
Mechinery
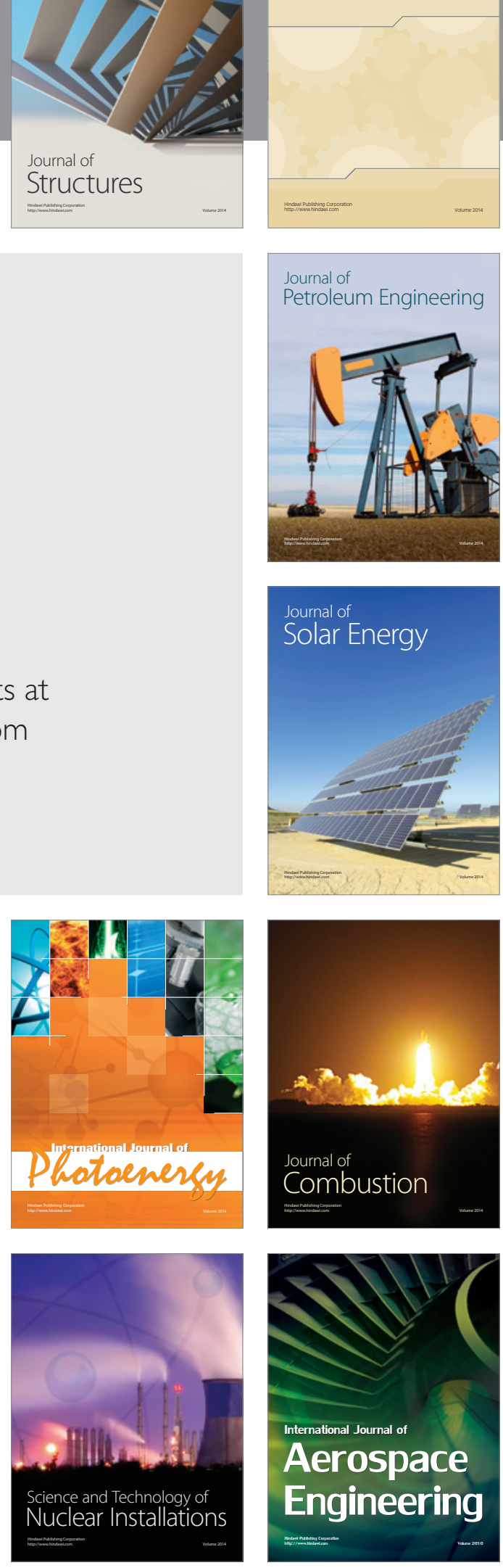